Article

\title{
Role of Trapped Air on the Tsunami-Induced Transient Loads and Response of Coastal Bridges
}

\author{
Denis Istrati *(D) and Ian Buckle \\ Department of Civil and Environmental Engineering, University of Nevada, Reno, 1664 N. Virginia Street, Reno, \\ NV 89557-0258, USA; igbuckle@unr.edu \\ * Correspondence: distrati@unr.edu; Tel.: +1-775-784-6937
}

Received: 9 February 2019; Accepted: 23 April 2019; Published: 25 April 2019

check for updates

\begin{abstract}
In response to the extensive damage of coastal bridges sustained in recent tsunamis, this paper describes an investigation into tsunami-induced effects on two common bridge types, an open-girder deck with cross-frames and one with solid diaphragms. To this end, large-scale (1:5) physical models with realistic structural members and elastomeric bearings were constructed and tested under a range of unbroken solitary waves and more realistic tsunami-like transient bores. The flexible bearings allowed the superstructure to rotate and translate vertically, thus simulating the wave-structure interaction during the tsunami inundation. Detailed analysis of the experimental data revealed that for both bridge types the resistance mechanism and transient structural response is characterized by a short-duration phase that introduces the maximum overturning moment, upward movement, and rotation of the deck, and a longer-duration phase that introduces significant uplift forces but small moment and rotation due to the fact that the wave is approaching the point of rotation. In the former phase the uplift is resisted mainly by the elastomeric bearings and columns offshore of the center of gravity of the superstructure (C.G.), maximizing their uplift demand. In the latter phase the total uplift is distributed more equally to all the bearings, which tends to maximize the uplift demand in the structural members close to the C.G. The air-entrapment in the chambers of the bridge with diaphragms modifies the wave-structure interaction, introducing (a) a different pattern and magnitude of wave pressures on the superstructure due to the cushioning effect; (b) a 39\% average and 148\% maximum increase in the total uplift forces; and (c) a 32\% average increase of the overturning moment, which has not been discussed in previous studies. Deciphering the exact effect of the trapped air on the total uplift forces is challenging because, although the air consistently increases the quasi-static component of the force, it has an inconsistent and complex effect on the slamming component, which can either increase or decrease. Interestingly, the air also has a complex effect on the uplift demand in the offshore bearings and columns, which can decrease or increase even more than the total deck uplift, and an inconsistent effect on the uplift force of different structural components introduced by the same wave. These are major findings because they demonstrate that the current approach of investigating the effect of trapped air only on the total uplift is insufficient. Last but not least, the study reveals the existence of significant differences in the effects introduced by solitary waves and transient bores, especially when air is trapped beneath the deck; it also provides practical guidance to engineers, who are advised to design the elastomeric bearings offshore of the C.G. for at least $60 \%$ and $50 \%$ of the total induced uplift force, respectively, for a bridge with cross-frames and one with diaphragms, instead of distributing the total uplift equally to all bearings.
\end{abstract}

Keywords: tsunami; experiments; bridge; air; wave-structure interaction; bore; solitary wave; deck; connections; bearings 


\section{Introduction}

Coastal bridges are critical assets for the prosperity of coastal communities, as well as for any rescue and recovery efforts after an extreme natural hazard. Despite their significance, coastal bridges located in seismic areas are currently not designed for tsunami forces, since tsunami design guidelines for bridges are currently non-existent. Recent tsunami events; however, demonstrated that such structures are vulnerable to the tsunami-induced loading. In fact, the 2004 Indian Ocean Tsunami washed away 81 bridges on the coast of Sumatra [1], while the tsunami generated by the 2011 Great East Japan earthquake damaged 252 bridges [2]. The most severe and common type of failure in these bridges was the breaking of the connections between the superstructure and the substructure, which resulted in the unseating and wash out of the bridge deck by the tsunami waves. This damage pattern was observed for different types of bridges including bridges with steel-girders and cross-frames (e.g., Koizumi Bridge), as well as bridges with pre-stressed or reinforced concrete girders and diaphragms (e.g., Utatsu Bridge). At a first glance, it seemed surprising that the bridges with concrete girders failed despite their large weight; however, as hypothesized by Kawashima and Buckle this might have happened due to the additional buoyancy forces generated by the air trapped between the girders and the bridge deck.

In an attempt to advance the understanding of tsunami-induced loading and reduce the vulnerability of coastal bridges, several studies have been conducted in recent years. These studies included (i) on-site surveys and damage analysis [3-5], (ii) small-scale wave flume experiments [6-10], and (iii) numerical simulations [11-16]. Several studies focused on the tsunami loads on flat slabs [8], while other studies examined more complex geometries such as decks with girders [2,7,17]. Most of the experimental studies were conducted at small to medium scales, ranging from 1:100 to 1:20, and the bridge models consisted of acrylic or wood decks supported rigidly, either from the top or the bottom of the deck, without considering the actual flexibility or inertia of the bridge.

A specific topic of interest in the coastal engineering community has been the trapped air between the girders of a bridge with diaphragms. McPherson [18] studied, experimentally, the hurricane induced wave forces on a 1:20 scale bridge model and observed the existence of trapped air during the inundation of the bridge. The study developed predictive force equations where the additional buoyancy due to the existence of air was considered, assuming that $50 \%$ of the volume between girders was filled with air. Bricker and Nakayama [11] who studied numerically the tsunami inundation of Utatsu Bridge in Japan, revealed that the trapped air between the girders increased the buoyancy of the bridge deck significantly resulting in the failure of the bridge. Hayatdavoodi et al. [19] noted that the trapped air increases the pressures below the bridge; however, it has not only a hydrostatic but also a hydrodynamic effect. Cuomo et al. [20] conducted hydraulic experiments of a bridge at 1:8 scale and observed that the holes in the bridge deck reduced the wave pressures on the deck slab but increased the ones on the longitudinal beams. The authors also noted the compression of the trapped air during the wave inundation acting as cushioning that reduces the max impulsive load and increases the load duration. Azadbakht and Yim [14] investigated, numerically, the impact of storm waves and Seiffert et al. [21] investigated, experimentally (1:35 scale), the impact of solitary waves on coastal bridges with trapped air, and both observed that the air-entrapment can significantly alter the water flow field during the wave inundation causing a significant increase in the uplift force. Bozognia et al. [22] and $\mathrm{Xu}$ et al. [23] conducted numerical studies and observed that the air-vents could reduce significantly the uplift force. However, a more recent study conducted by Qu et al. [24] revealed that this is not always true, and in fact openings in the deck can increase the uplift forces when the bridge girders are partially inundated.

Among the studies focusing on the role of air-entrapment and venting, some of them used periodic waves, while others used solitary waves. Although solitary waves have been traditionally used to simulate tsunamis, the recent studies by Madsen et al. [25] and Chan and Liu [26] noticed differences in the wave characteristics (e.g., wave profile and wavelength) of solitary waves and tsunamis. Moreover, the studies by Leschka and Oumeraci [27] and Istrati et al. [28], which investigated the loading of solitary waves and bores on vertical cylinders and bridges, respectively, revealed the existence of substantial differences between the forces caused by two wave types. Therefore, despite 
the simplicity and convenience of solitary waves, using more complex type waves such as bores might be a necessity. To this end, the current investigation attempts to advance the understanding of the trapped air developed in previous studies, via hydrodynamic experiments which considered both solitary waves and more realistic bores. Other features that add to the novelty of the work presented herein include the:

- Large scale (1:5) of the experiments, which enabled the physical modeling of a realistic bridge deck with structural components used in current practice, such as a reinforced concrete deck, steel girders, cross-frames, shear-keys, etc;

- Flexible elastomeric bearings that allowed the deck to move vertically and rotate along the longitudinal axis, simulating; therefore, the wave-structure interaction during the tsunami inundation; and

- Experimental setup, which permitted the measurement of not only the total horizontal and uplift forces but the demand in individual bearings, columns, shear keys, and bent cap.

\section{Experimental Program}

\subsection{Facility and Flume Bathymetry}

The experiments were conducted in the Large Wave Flume (LWF) at the O.H. Hinsdale Wave Research Laboratory (HWRL) at Oregon State University. The flume is $104.24 \mathrm{~m}$ long, $3.66 \mathrm{~m}$ wide, and $4.57 \mathrm{~m}$ deep. The LWF is equipped with a piston-type dry-back wave-maker with a $4.2 \mathrm{~m}$ maximum stroke hydraulic actuator assembly, which can generate up to $1.40 \mathrm{~m}$ high solitary waves for a water depth equal to $2.0 \mathrm{~m}$. The flume has an adjustable bathymetry made of 20 square configurable concrete slabs and includes a series of bolt-holes in vertical patterns every $3.66 \mathrm{~m}$ along the flume, for supporting test specimens as well as the concrete bathymetry slabs. For this project a slope of 1:12 at the beginning, followed by a horizontal bathymetry of $40.2 \mathrm{~m}$ long and another 1:12 slope at the end of the flume for dissipating waves was selected (Figure 1). The slope at the beginning will cause a decrease of the water depth, which will influence the wave and, as a result, the wave height will increase during propagation due to shoaling and, depending on the ratio of the wave height/water depth, it will break and form a bore. In addition, the optimum location for the bridge was between bays 14 and 15, in order to allow for the bore to form after the wave breaking and still inundate the bridge. Therefore, this setup allowed the testing of both unbroken solitary bores and more realistic tsunami bores, by varying just the wave height of the generated wave at the wave-maker location.

\subsection{Bridge Description and Experimental Setup}

In the hydrodynamic experiments a composite bridge model with a reinforced concrete deck and four steel I-girders was designed and constructed at a 1:5 scale. The in-plane dimensions of the bridge deck are $3.45 \mathrm{~m}$ length and $1.94 \mathrm{~m}$ width, and the steel girders are connected with cross-frames at the end supports and at third points. The thickness of the slab is $5.1 \mathrm{~cm}$, the haunch is $1.0 \mathrm{~cm}$, and the height of the steel girders (W8x13) is $21.3 \mathrm{~cm}$. The bridge model was connected to the bent caps with plain elastomeric bearings. The bearing dimensions were $6.5 \mathrm{~cm}$ diameter and $1.27 \mathrm{~cm}$ height. Shear keys were also designed to take the lateral earthquake load and transfer it to the bent caps. The bearings and the shear keys correspond to realistic flexible connections which allow rotations and vertical displacements of the deck but restrict the horizontal displacements. These flexible bearings where designed for thermal expansion and their properties were scaled down by the Froude number, yielding a fundamental period of $0.19 \mathrm{~s}$ for the scaled (1:5) bridge specimen, which translates into a $0.43 \mathrm{~s}$ period for a real-size bridge. This period is typical for regular real-size bridges, which means that their behavior is expected to exhibit similarities with the one observed in the experiments presented herein.

In practice, the bent caps and all the structural components above (deck, bearings, shear keys, etc.) are supported on columns that transfer the loads to the foundations and eventually the ground. However, due to space limitations in the flume and the objective of the investigators to construct the 
largest possible deck, the actual columns were not constructed in the experiments, but instead a testing frame $[29,30]$, consisting of linear guide rails, carriages with rollers, two beams (W18x76), and two brackets bolted to the flume walls (one on each wall), was used to support the deck. The wave loads were transferred from the deck to the walls, via a horizontal substructure link and three vertical load cells on top of the rollers/carriages, resembling a bent cap with three columns.

All the structural members of the bridge (e.g., deck, girders, cross-frames, bearings, and shear keys) were designed according to AASHTO LRFD Bridge Design Specifications [31], while the other components of the experimental setup (e.g., connecting plates, load cells, rollers, and rails) were designed to resist the expected tsunami loading so that it can be transferred to the walls. Due to the large number of structural elements and bolted connections with tight tolerances, the setup was constructed and pre-assembled in dry conditions at the University of Nevada, Reno (Figure 2) to ensure that everything fitted together, and then shipped to Oregon State University for testing in the flume. The hydrodynamic testing included several bridge configurations and parameters of investigation; however, this paper will present results from two configurations, namely case ST2 and ST5, which represent two commonly used bridge types in coastal areas. The former configuration had cross-frames between the girders, which allowed the air to escape from the sides, while in the latter one plywood diaphragms were bolted to the cross-frames, tight fitted between the girders and the deck, and sealed with caulk in order to simulate solid diaphragms that prevent the escape of the trapped air from the sides.

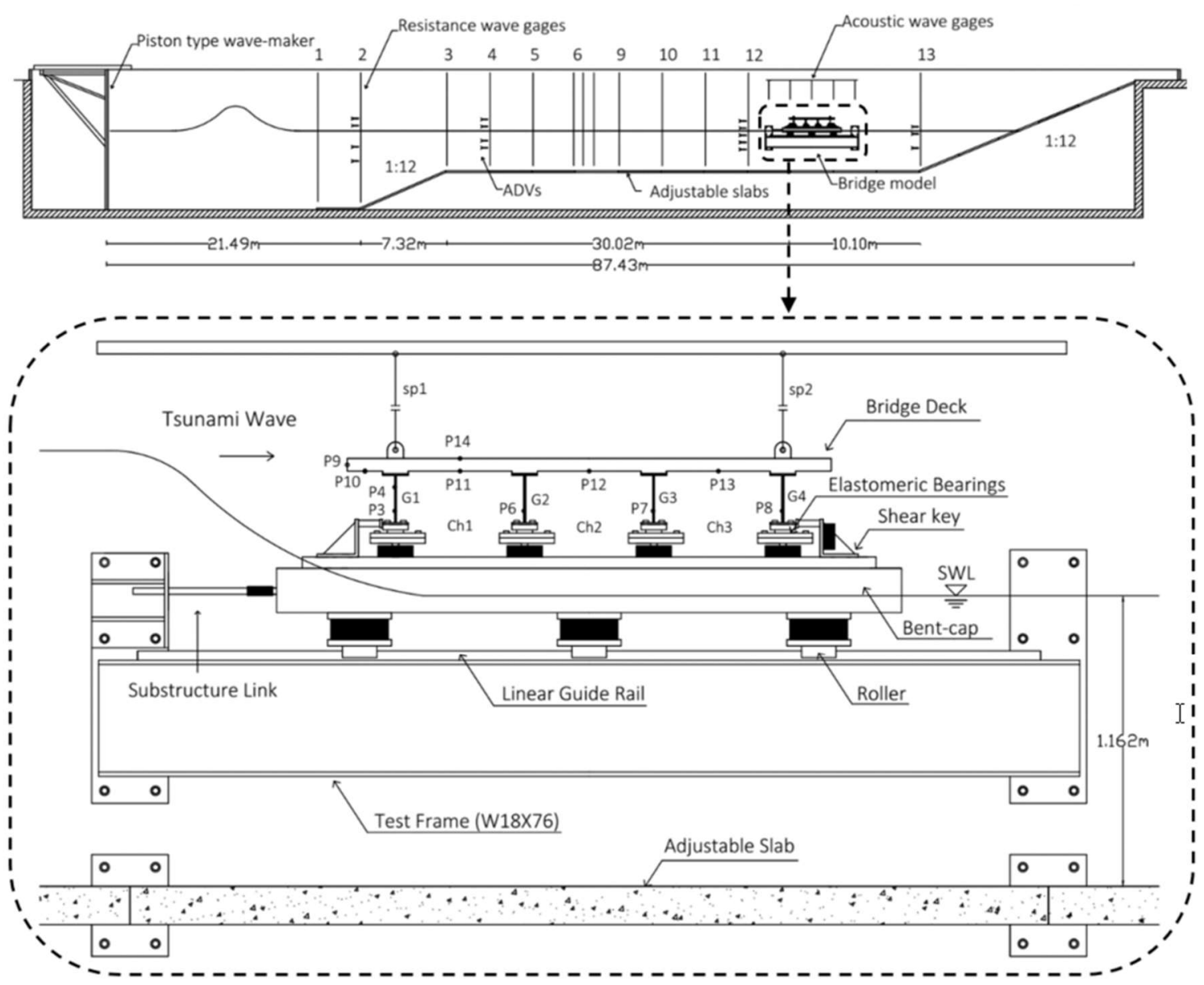

Figure 1. Experimental setup of the hydrodynamic experiments depicting the wave flume (top) and the bridge model (bottom), with the main components and the corresponding instrumentation. (SWL = still water depth, $\mathrm{G}=$ girder, $\mathrm{Ch}=$ chamber, $\mathrm{P}=$ pressure gage, $\mathrm{sp}=$ string pot). 

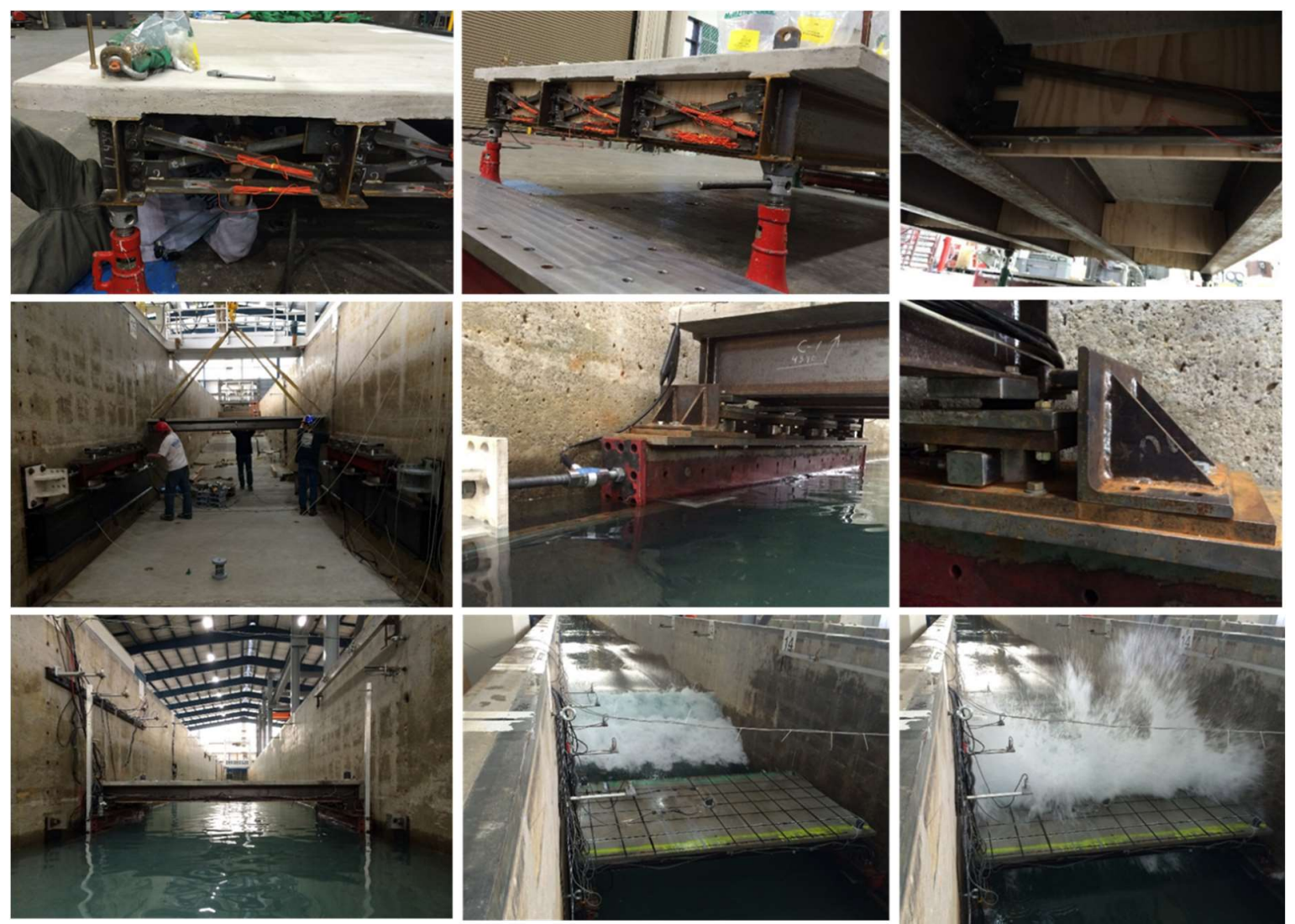

Figure 2. Bridge deck with cross-frames and diaphragms during the dry pre-test assembly in the Large-Scale Structures Laboratory at the University of Nevada, Reno (top), the set-up in the wave flume (center), and the hydrodynamic testing (bottom).

\subsection{Wave Matrix}

As explained in the introduction, one of the main objectives of this study was to investigate the wave-induced effects on coastal decks from both solitary waves and more realistic tsunami-like transient bores, and examine the sensitivity of applied loading and structural response to the different wave types. To this end, a wave matrix was carefully selected which included two different wave depths, $1.90 \mathrm{~m}$ and $2.00 \mathrm{~m}$, and a range of wave heights from $0.36 \mathrm{~m}$ to $1.40 \mathrm{~m}$, shown in Table 1 . These water depths and wave heights are the prescribed/nominal values (" $\mathrm{H}$ " or "Hinput") at the wave-maker location, while at the bridge location the two water depths are $1.06 \mathrm{~m}$ and $1.16 \mathrm{~m}$, respectively. Table 2 shows the measured wave heights at $\mathrm{wg} 2$, which is located at a distance of $21.49 \mathrm{~m}$ from the wave-maker and at wg12 and uwsg1, which are located at distance of $4.44 \mathrm{~m}$ and $0.92 \mathrm{~m}$ from the offshore face of the bridge deck, respectively. As shown in the table, the wave heights of the unbroken solitary waves are increased by about $11-38 \%$ (due to shoaling) and of the bores are reduced by $10-50 \%$ (due to wave breaking), depending on the wave height. Moreover, at wg2 the wave heights of all the tested waves for ST2 and ST5 seem to be very similar with a mean difference of $0.8 \%$ and a max difference of $4 \%$, which means that the waves are very repeatable close to the wave-maker. At wg12 and uswg1, the measured wave heights of the transformed unbroken solitary waves have, respectively, a difference of $0.4 \%$ or $0.9 \%$ on average, and $5 \%$ or $4 \%$ max, between the two deck types. On the other hand, the agreement of the bore heights at the two locations is not as good, with the mean difference being $3.9 \%$ or $5.2 \%$, the maximum difference $22 \%$ or $19 \%$, and the coefficient of variation equal to $9.8 \%$ or $8.9 \%$, at w12 and uswg1, respectively. These larger mean values are governed by two bore heights, the one with $\mathrm{H}=1.30 \mathrm{~m}$ and partially by $\mathrm{H}=0.80 \mathrm{~m}$, and if these too are not considered then the new mean values drop to similar levels with the solitary waves. 
Table 1. Wave matrix used in the experimental testing of the bridge with elastomeric bearings.

\begin{tabular}{ccc}
\hline Wave Type & Nominal Wave Height $(\mathbf{m})$ & Water Depth (m) \\
\hline \multirow{2}{*}{ Unbroken Solitary Wave } & $0.46,0.52,0.65$ & $1.90(1.06)$ \\
& $0.36,0.42,0.50,0.55,0.62,0.70$ & $2.00(1.16)$ \\
\hline \multirow{2}{*}{ Bore } & $0.80,1.00,1.10,1.30$ & $1.90(1.06)$ \\
& $0.80,0.90,1.00,1.20,1.40$ & $2.00(1.16)$ \\
\hline
\end{tabular}

Table 2. Measured wave heights at three wave gauges.

\begin{tabular}{|c|c|c|c|c|c|c|c|c|c|c|}
\hline \multirow[b]{2}{*}{$\mathrm{d}(\mathrm{m})$} & \multirow[b]{2}{*}{$\mathrm{H}(\mathrm{m})$} & \multicolumn{3}{|c|}{ ST2 } & \multicolumn{3}{|c|}{ ST5 } & \multicolumn{3}{|c|}{ Ratios ST5/ST2 } \\
\hline & & $\begin{array}{c}\text { Hwg2 } \\
\text { (m) }\end{array}$ & $\begin{array}{c}\text { Hwg12 } \\
\text { (m) }\end{array}$ & $\begin{array}{l}\text { Huswg1 } \\
\text { (m) }\end{array}$ & $\begin{array}{c}\text { Hwg2 } \\
\text { (m) }\end{array}$ & $\begin{array}{c}\text { Hwg12 } \\
\text { (m) }\end{array}$ & $\begin{array}{l}\text { Huswg1 } \\
\text { (m) }\end{array}$ & Hwg2 & Hwg12 & Huswg1 \\
\hline \multirow{7}{*}{1.90} & 0.46 & 0.48 & 0.58 & 0.60 & 0.46 & 0.55 & 0.60 & 0.96 & 0.95 & 1.00 \\
\hline & 0.52 & 0.54 & 0.67 & 0.71 & 0.54 & 0.66 & 0.68 & 1.00 & 0.99 & 0.96 \\
\hline & 0.65 & 0.66 & 0.91 & 0.91 & 0.67 & 0.89 & 0.91 & 1.02 & 0.98 & 1.00 \\
\hline & 0.80 & 0.80 & 0.72 & 0.65 & 0.80 & 0.82 & 0.77 & 1.00 & 1.13 & 1.19 \\
\hline & 1.00 & 0.99 & 0.69 & 0.74 & 0.99 & 0.75 & 0.69 & 0.99 & 1.08 & 0.94 \\
\hline & 1.10 & 1.09 & 0.77 & - & 1.07 & 0.72 & 0.75 & 0.98 & 0.94 & - \\
\hline & 1.30 & 1.29 & 0.61 & 0.66 & 1.31 & 0.74 & 0.78 & 1.02 & 1.22 & 1.19 \\
\hline \multirow{11}{*}{2.00} & 0.36 & 0.37 & 0.41 & 0.43 & 0.38 & 0.42 & 0.43 & 1.02 & 1.01 & 1.00 \\
\hline & 0.42 & 0.43 & 0.49 & 0.52 & 0.44 & 0.50 & 0.51 & 1.02 & 1.01 & 1.00 \\
\hline & 0.55 & 0.55 & 0.66 & 0.72 & 0.56 & 0.68 & 0.70 & 1.00 & 1.02 & 0.97 \\
\hline & 0.70 & 0.69 & 0.90 & 0.97 & 0.70 & 0.91 & 0.97 & 1.02 & 1.01 & 1.00 \\
\hline & 0.90 & 0.87 & 0.96 & 0.87 & 0.88 & 0.88 & 0.88 & 1.01 & 0.92 & 1.00 \\
\hline & 1.00 & 0.94 & 0.78 & 0.83 & 0.98 & 0.80 & 0.80 & 1.04 & 1.03 & 0.97 \\
\hline & 1.20 & 1.14 & 0.82 & 0.79 & 1.16 & 0.75 & 0.84 & 1.02 & 0.92 & 1.07 \\
\hline & 1.40 & 1.35 & 0.73 & 0.82 & 1.37 & 0.79 & 0.83 & 1.02 & 1.07 & 1.01 \\
\hline & & & & & & & Mean & 1.01 & 1.02 & 1.02 \\
\hline & & & & & & & $\mathrm{SD}$ & 0.02 & 0.08 & 0.07 \\
\hline & & & & & & & CV (\%) & 1.78 & 7.75 & 7.23 \\
\hline
\end{tabular}

$\mathrm{d}=$ water depth at the wavemaker location, $\mathrm{H}=$ nominal/targeted wave height at the wavemaker location. Hwg2, Hwg12 = wave heights measured at the location of the resistance waves gages 2 and 12, respectively. Huswg1 = wave heights measured at the location of the acoustic wave gage 1.

The main reason for seeing a larger difference/variability in the wave heights of the bores close to the bridge is the fact that these bores were formed after the occurrence of wave breaking, which is a very complex process consisting of multiple plunges, oblique splash-up, vertical jet, air bubble entrainment, and chaotic multiple splash-up events that produce vorticity and turbulence, as described by Ghosh et al. [32]. Therefore, the variability in the bore heights at wg12 and uswg1 can be justified by the randomness associated with the plunging wave breaking process, and it should be taken into account when the wave-induced effects on the two bridge configurations are compared.

It is noteworthy that after the 2011 Tohoku Tsunami in Japan, Hoshikuma et al. [17] identified two failure modes for the damaged bridges, one that was caused by bores and another one caused by gradual rising of the water level. Given the fact that bores generate a complex hydrodynamic loading that has not been understood, the previous authors conducted scaled (1:20) experiments of tsunami bore impact on bridges utilizing a dam-break approach. Interestingly, the experimental results revealed that the maximum applied loading on the deck (horizontal and vertical) occurred during the transient inundation phase, as the deck was being impacted and inundated, and not during the long duration flow that occurred after the bridge was totally inundated. Therefore, the objective of the present study was to advance the understanding of the transient part of the tsunami bore loading, which generated the worst-case scenario for bridges. This means that the experiments presented herein did not attempt to represent the period of an actual tsunami, but instead aimed at generating transient tsunami-like bores in front of the bridge, which had realistic heights and velocities, and were long enough to 
inundate the whole bridge. The above objective was successfully achieved via extensive parametric computational fluid dynamics (CFD) analyses that were conducted prior to the experimental work, and determined a wave matrix that included bores with heights in the range of $0.65-0.87 \mathrm{~m}$ and velocities in the range of $2.8-5 \mathrm{~m} / \mathrm{s}$. Scaling up these numbers to real-size conditions, yields bores with heights in the range of $3.25-4.35 \mathrm{~m}$ and velocities between $6.2-11.2 \mathrm{~m} / \mathrm{s}$. These numbers are consistent with past records of the 2011 tsunami, according to which the flow velocities reached $6-10 \mathrm{~m} / \mathrm{s}$. It must be clarified at this point that the phrases "tsunami bores," "tsunami-like bores," and "tsunami loading," used in the following sections of the current manuscript, will point out to the transient part of a tsunami bore, as explained above.

\subsection{Instrumentation and Calculated Quantities}

Wave hydrodynamics were measured in the experiments using resistive-type wave gauges, acoustic probes, pressure gauges, and Acoustic Doppler Velocimeters (ADVs), at the locations shown in Figure 1. The wave gauges were installed along the flume to measure the free-surface elevation and capture the propagation of the waves and the complex phenomenon of wave breaking. Moreover, five acoustic probes were installed at the location of the bridge deck to track the overtopping process, and sixteen Vectrino-II ADVs were installed at four different locations along the flume to track the particle velocities, with three to five ADVs installed at different elevations of each of these locations in order to determine the velocity profile. In addition to the extensive flume instrumentation, the bridge was heavily instrumented in order to measure both the tsunami impact pressures, as well as the bridge response in terms of accelerations, displacements, strains, and member forces. To this end, twelve pressure gauges were installed on the steel girders and on the concrete deck, as shown in Figure 1. In addition, three biaxial accelerometers together with two vertical and two horizontal string pots were installed on top of the concrete deck, to capture the bridge response along the horizontal and vertical direction. In particular, two accelerometers and two string pots (sp1 and sp2 in Figure 1) were installed at the location of the offshore and onshore lifting lugs, measuring the vertical displacements and enabling the calculation of the cumulative rotation (angle $\varphi$ ) of the deck relative to its initial position, using the following equation:

$$
\begin{gathered}
\varphi=\arcsin [(\mathrm{dz} 1-\mathrm{dz} 2) / \mathrm{Lsp}] \\
\mathrm{dzi}=\mathrm{dz}, \mathrm{spi} \pm \tan \delta \times \mathrm{dx}
\end{gathered}
$$

where the angle $\varphi$ is in rad; dz1 and dz2 are the vertical displacements (histories) of the offshore and onshore lifting lug; Lsp is the horizontal distance between the two lifting lugs, dz; spi is the measured shortening/elongation of the vertical string pot $\mathrm{I}$; and $\mathrm{dx}$ is the horizontal displacement of the deck. Since both bridge configurations presented herein have a rigid horizontal substructure link and shear keys, the horizontal displacements of the substructure and the deck are negligible relative to the vertical ones, which means that the second term in Equation (2) can be eliminated.

Last but not least, sixteen submersible load cells (shown with a black solid hatch in Figure 1) were installed to measure the forces in certain members and connections. Six of these load cells were installed below the bent caps to measure the uplift forces in the bent-cap to column connections. These load cells represent axially stiff (rigid) columns and in this manuscript they will be called "columns" for the sake of simplicity. The two load cells installed on the shear keys and the two on the substructure link measured the horizontal forces at two different levels, while the eight load cells below the bearings and the six load cells below the bent cap measured the vertical forces in bearings and columns, respectively. Using the measured forces, the wave-induced moment was calculated as shown in [28]. 


\section{Results: Deck with Cross-Frames}

\subsection{Total Forces and Moments}

Figure 3 shows the time-histories of recorded vertical and horizontal forces, together with the calculated moments, for three selected solitary waves and three bores. The origin $(t=0)$ of all the time series presented in the manuscript is the instant that the wave-maker starts moving, which explains why waves of different heights impact the bridge at a different point in time. In these graphs the positive values indicate lateral horizontal loads in the direction of the wave flow, uplift forces, and clock-wise moments. Examination of the figure reveals that all the tested waves introduced significant uplift forces followed by a large downward force. In fact, the vertical force histories are characterized by a short-duration impulsive uplift at the time of the initial impact of the wave on the offshore side of the deck, followed by a longer duration (slowly varying) uplift force as the inundation of the bridge progresses, which is consistent with previous studies (e.g., [7,17]). Notably, depending on the wave type and height, the maximum uplift force can occur either during the impulsive uplift or the slowly-varying uplift phase. However, the maximum overturning moment is generated always at the beginning of the bridge inundation, which can be attributed to the simultaneously large magnitude of the impulsive horizontal and uplift force and the fact that the latter force is applied below the offshore overhang, generating a large moment arm relative to the center of gravity (or the onshore point of rotation) and, consequently, a large overturning moment (OTM). As the wave propagates through the bridge, the uplift force can increase for some wave heights; however, the moment arm decreases resulting in reduced OTMs. These large OTMs have also been observed in previous studies (e.g., $[11,15,17])$ but their temporal variation and effect on the structural components has not yet been fully understood. A detailed discussion of the role of OTM for bridge decks with steel bearings is presented in [28].

(a)

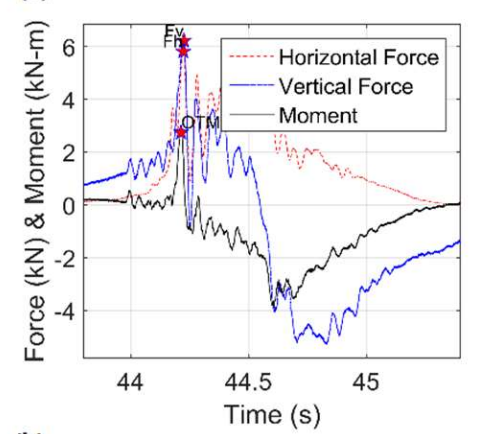

(b)

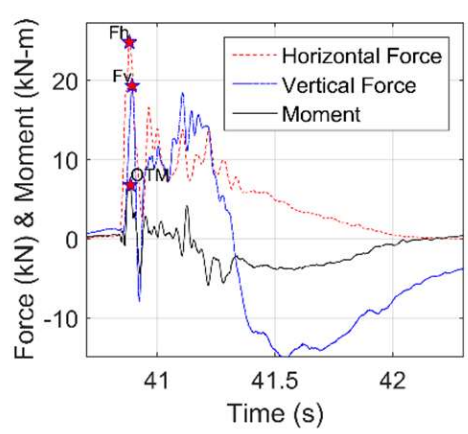

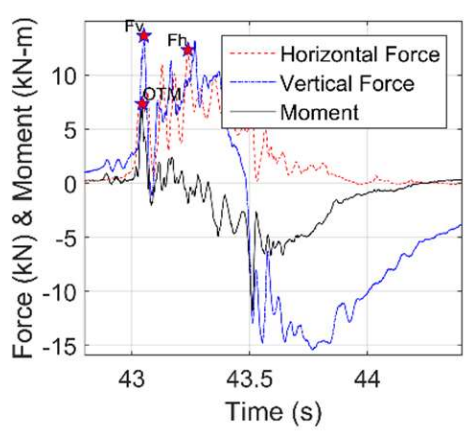

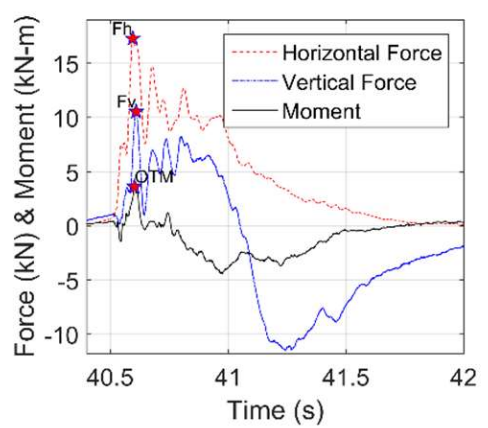

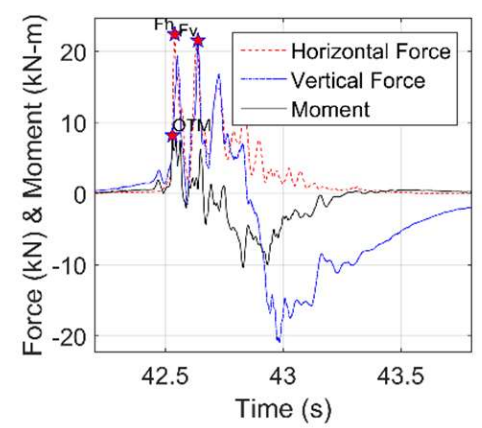

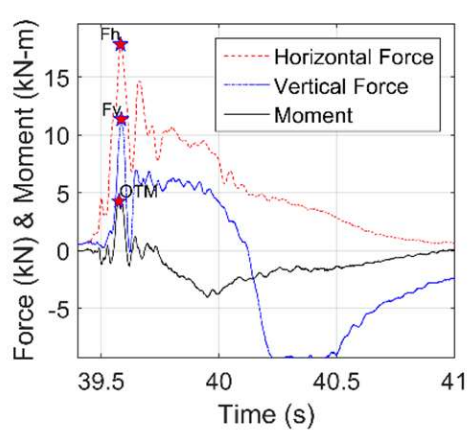

Figure 3. Wave-induced forces and moments for (a) solitary waves (top) with $\mathrm{H}=0.42 \mathrm{~m}$ (left), $\mathrm{H}=0.55 \mathrm{~m}$ (center), and $\mathrm{H}=0.65 \mathrm{~m}$ (right); and (b) bores (bottom) with $\mathrm{H}=0.90 \mathrm{~m}$ (left), $\mathrm{H}=1.00 \mathrm{~m}$ (center), and $\mathrm{H}=1.30 \mathrm{~m}$ (right). 


\subsection{Structural Response}

Figure 4 presents the vertical displacements measured by the two string pots and the cumulative rotation of the deck (angle $\varphi$ ) relative to its initial position calculated from Equation (1). Positive values indicate upward translation and clockwise rotation. To be able to plot the displacements and rotations on the same graph and clearly visualize the trends, the rotation histories were multiplied by a factor of 15 . As expected, when the wave impacts the offshore side of the bridge (girder and overhang) the offshore girder moves upward while the onshore girder has a negligible movement, which generates a clockwise rotation. As the flooding of the deck continues and the wave reaches the interior girders and chambers, the upward offshore displacement and clockwise rotation is reduced, while the onshore upward displacement increases. At some point the offshore side of the deck starts moving downwards, and the deck begins to rotate counter-clockwise and this longer duration movement continues until the end of the inundation, at which point the deck moves back to its initial position. Noticeably, the displacement and rotation histories can differ significantly between different wave heights of the same wave type-for example, $\mathrm{H}=0.55 \mathrm{~m}$ vs. $\mathrm{H}=0.65 \mathrm{~m}$ (solitary), or $\mathrm{H}=0.90 \mathrm{~m}$ vs. $\mathrm{H}=1.30 \mathrm{~m}$ (bores)-with some waves showing additional counter-clockwise rotation peaks between the short-duration clockwise rotation at the beginning of the inundation and the long duration counter-clockwise rotation towards the end, indicating a more complex wave-structure interaction. Despite these differences, all the tested waves generated the maximum rotation (clockwise) and upward displacement when the wave impacted the offshore side of the bridge.
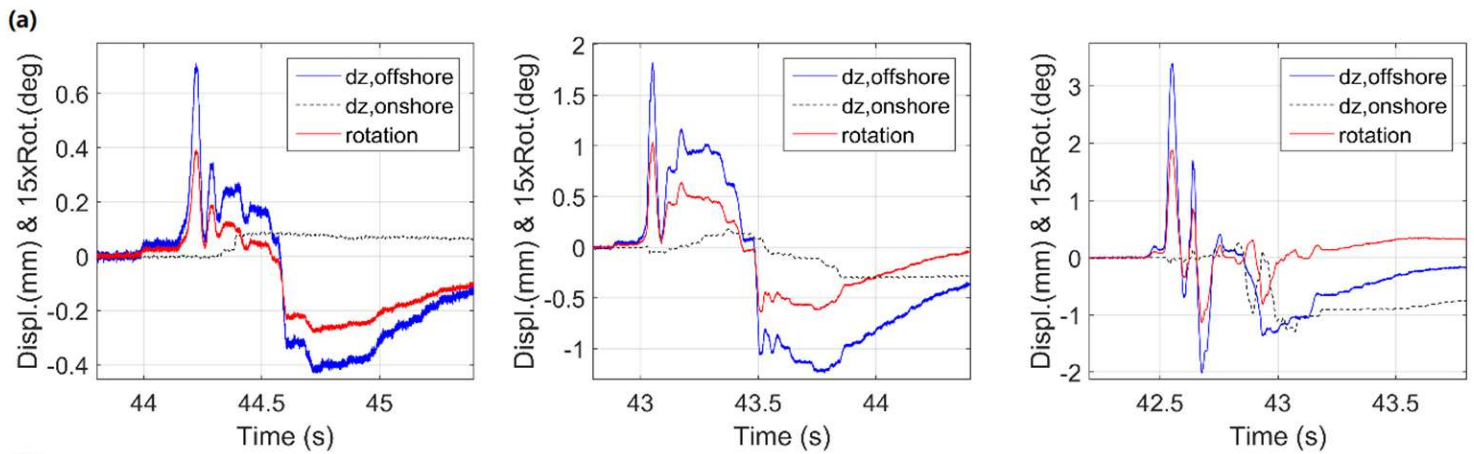

(b)
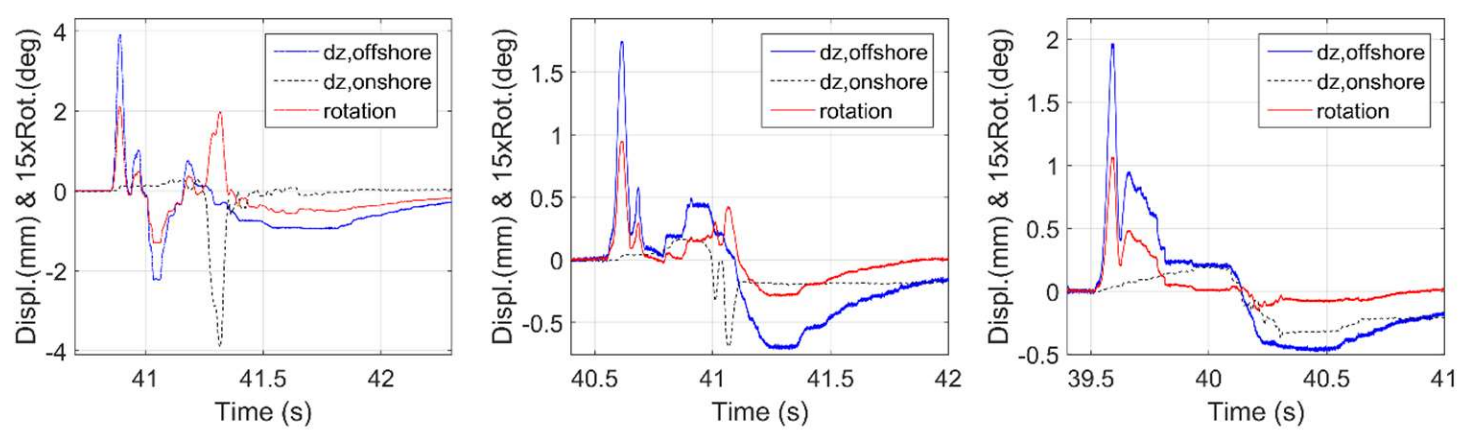

Figure 4. Deck vertical displacements and cumulative rotation for (a) solitary waves (top) with $\mathrm{H}=0.42 \mathrm{~m}$ (left), $\mathrm{H}=0.55 \mathrm{~m}$ (center), and $\mathrm{H}=0.65 \mathrm{~m}$ (right); and (b) bores (bottom) with $\mathrm{H}=0.90 \mathrm{~m}$ (left), $\mathrm{H}=1.00 \mathrm{~m}$ (center) and $\mathrm{H}=1.30 \mathrm{~m}$ (right). (dz, offshore and $\mathrm{dz}$, onshore = vertical displacement of the offshore and onshore lifting lugs respectively).

Another interesting finding to emerge from this figure is that although previous studies assumed the point of rotation to be the bottom of the onshore girder, for bridges with elastomeric bearings this might not be the case. In such cases the bearing flexibility allows the onshore girder to move upwards and downwards indicating that this is not always the point of rotation. 


\subsection{Member Forces and Resistance Mechanism}

To decipher the tsunami-induced forces and resistance mechanism, Figure 5 attempts to relate the observed effects to the transient bridge inundation process. To this end, it presents non-dimensional time-histories of bearing vertical forces (Fv,brgns, Gi), deck total vertical force and induced moment, applied pressures below the deck, displacements and cumulative rotation (angle $\varphi$ ), which are normalized by their respective maximum values. The graphs demonstrate that the inundation process and response of a bridge deck with elastomeric bearings can be characterized by four different phases, as shown below:

- Phase 1: This phase starts at the time of the first wave impact on the offshore side of the deck, at which point the impulsive (slamming) uplift and horizontal forces together with the overturning moment are maximized. This short-duration loading introduces significant upward movement of the deck and the maximum clockwise rotation, which translates into uplift of several offshore structural components (bearings and columns) and compression of the onshore ones. In this phase the tsunami demand is resisted mainly by bearings G1 and G2, and partially by G3, which explains why this phase creates the worst-case scenario for the former members. Following the impulsive uplift, the downward pressure on the top side of the bottom flange of the I-girder and the dynamic structural effects are reducing the deck uplift force down to zero (can even become negative) and are causing a counter-clockwise rotation that tends to bring the deck close to its initial position, before the wave impacts chamber 1 .

- Phase 2: As the wave propagates and reaches chamber 1 ("Ch1" in Figure 1), the uplift force and clockwise moment and rotation start increasing again. The increase of the uplift force continues until the wave reaches chamber 2; however, the moment decreases significantly since the wave is approaching the center of gravity (C.G.) and the point of rotation (moment arm goes down), and that is why the bridge does not rotate much in this phase. This demonstrates that the structural response of the bridge is governed by a translational mode in the vertical direction, which tends to uplift the whole deck and introduce the maximum uplift demand in the members close to the C.G. of the bridge (e.g., bearings G3 and col. 2).

- Phase 3: In this phase the wave reaches the onshore chamber (Ch3), applying significant uplift on the deck and a counter-clockwise moment (negative value). This moment introduces counter-clockwise rotation of the deck, which is evidenced in Figure 5 by the reduction of the $\varphi$ angle, which continues until the deck is perfectly leveled again. This phase is significant because it generates the maximum uplift in the onshore bearings. The phase ends when the wave has flooded all the chambers and it starts overtopping the deck.

- $\quad$ Phase 4: The last phase occurs when the wave slams the top surface of the deck and gradually overtops and inundates the whole deck. At the instant of the wave slamming (close to P14 in Figure 1) a localized maximum downward force peak with a significant counter-clockwise moment and deck rotation is introduced by most waves. The phase introduces the maximum downward force on the deck and puts all bearings and columns in compression.

Although the structural response and resistance mechanism of a deck with flexible connections (elastomeric bearings) and shear keys is different than the ones of a deck with steel bearings presented in [28], there are many similarities in the four phases especially in terms of induced total forces and moments. In regards to the resistance mechanism of the decks presented herein, the mechanism changes in the different phases, because in Phase 1 the uplift loading is mainly resisted by the offshore bearings G1 and G2, while in Phases 2 and 3 the loading is distributed to all bearings. This finding has implications for the tsunami design of decks with beams and overhangs, because it demonstrates that although the maximum uplift force might not always occur during the initial impact of the wave on the structure (phase 1), this phase introduces always the maximum uplift in the offshore vertical members and connections. If the offshore bearings, columns or connections fail during phase 1 , then 
the loading will be re-distributed to the rest of the members, which could exceed their capacity and gradually lead to a progressive failure and unseating of the deck.

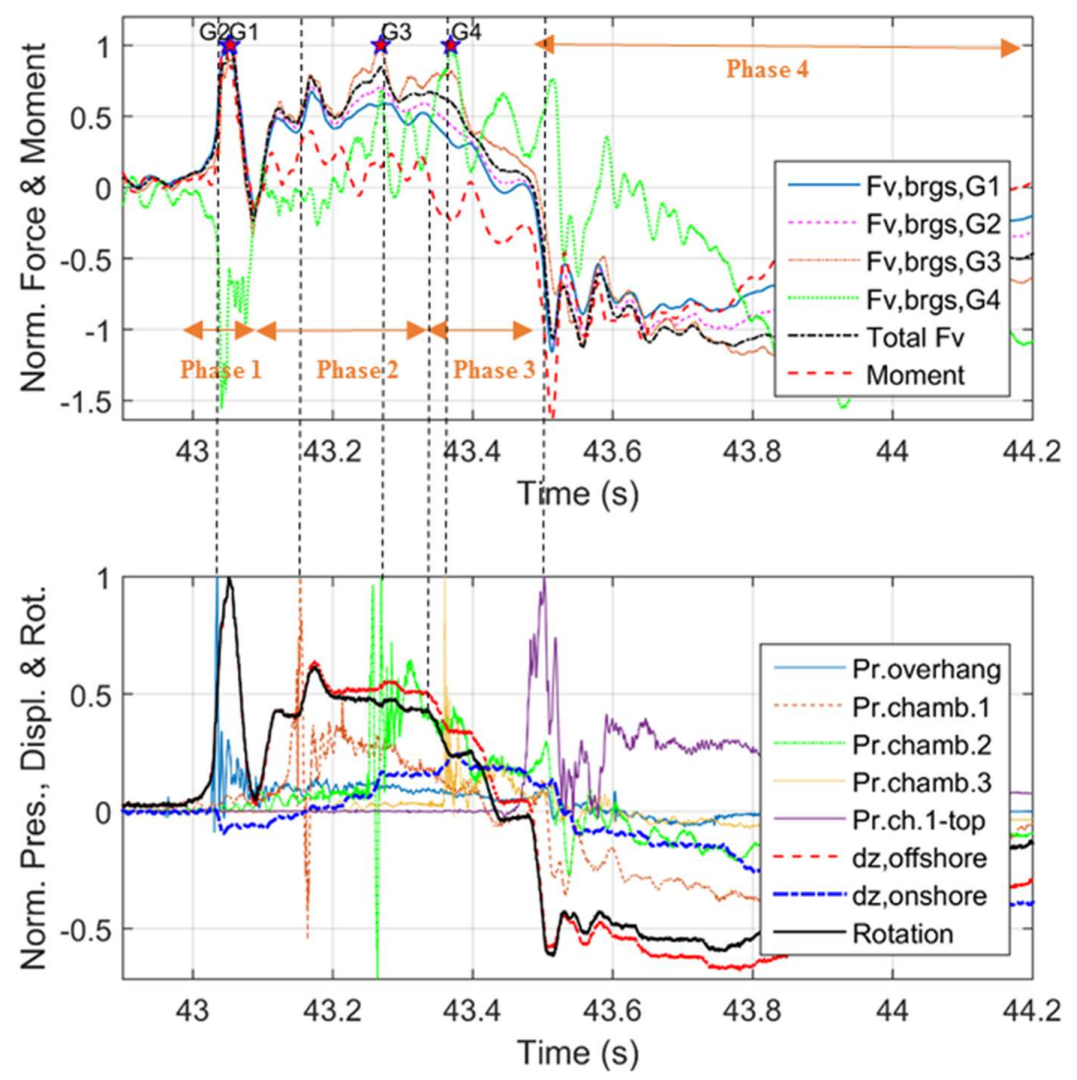

Figure 5. Time histories of normalized vertical forces and moments (top), and normalized pressures, vertical displacements and cumulative rotations (bottom) for $\mathrm{H}=0.55 \mathrm{~m}$.

\section{Solid Diaphragms vs. Cross-Frames}

\subsection{Pressures on Girders and Below the Deck}

This section will attempt to identify the differences in the tsunami-induced effects that bridge decks with cross-frames (ST2) or solid diaphragms (ST5) have to withstand. As explained in Section 2, the main difference between the two specimens is that the second one has plywood sheets attached at the locations of the intermediate and end cross-frames, which act as diaphragms that trap the air during the bridge inundation. Figures 6 and 7 show the pressure histories applied at different locations of the bridge deck, for a selected solitary wave and bore. Given the inherent variability of wave breaking bore formation and induced forces on structures [32-36], it is critical to ensure that the waves inundating the two decks are identical, before any meaningful comparison can be conducted. The wave heights measured at several gauges have been compared and presented in Section 2 of this paper. Moreover, the top-left graph in each of the aforementioned figures shows the applied pressures on the offshore face of the offshore girder, which is not affected by the existence of the trapped air, verifying that these pressure histories are fairly similar in both bridge cases.

In contrast to the aforementioned pressures, Figure 6 shows that the pressure on the internal girders G2 and G3 and in the three chambers below the deck are totally different for the two deck types, when impacted by a solitary wave. One of the main differences lies in the fact that in the case of solid diaphragms (ST5) the pressures are reaching a maximum value before they do in ST2. This is most likely because for this deck type there is significant air entrapment between the girders, diaphragms, and the wave that is compressed, transferring the pressures on the girder and the deck before the crest 
of the wave reaches these locations. Another difference between the two specimens is the fact that the bridge with diaphragms (ST5) has two distinctive peaks in both the pressures on the girder and on the deck and can probably be related to the wave-air interaction and the cushioning effect, due to the compressibility of the air, as the flooding of the chambers progresses. Regarding the magnitude of the pressure, the air entrapment seems to have a smaller effect on the horizontal pressure (girder) relative to the effect on the pressures below the deck, with ST5 witnessing approximately three times higher vertical pressures due to the air entrapment. In addition, the trapped air seems to be smoothing out the peaks of the pressure histories and increase their duration, as was also seen in the experimental study by Cuomo et al. [20].
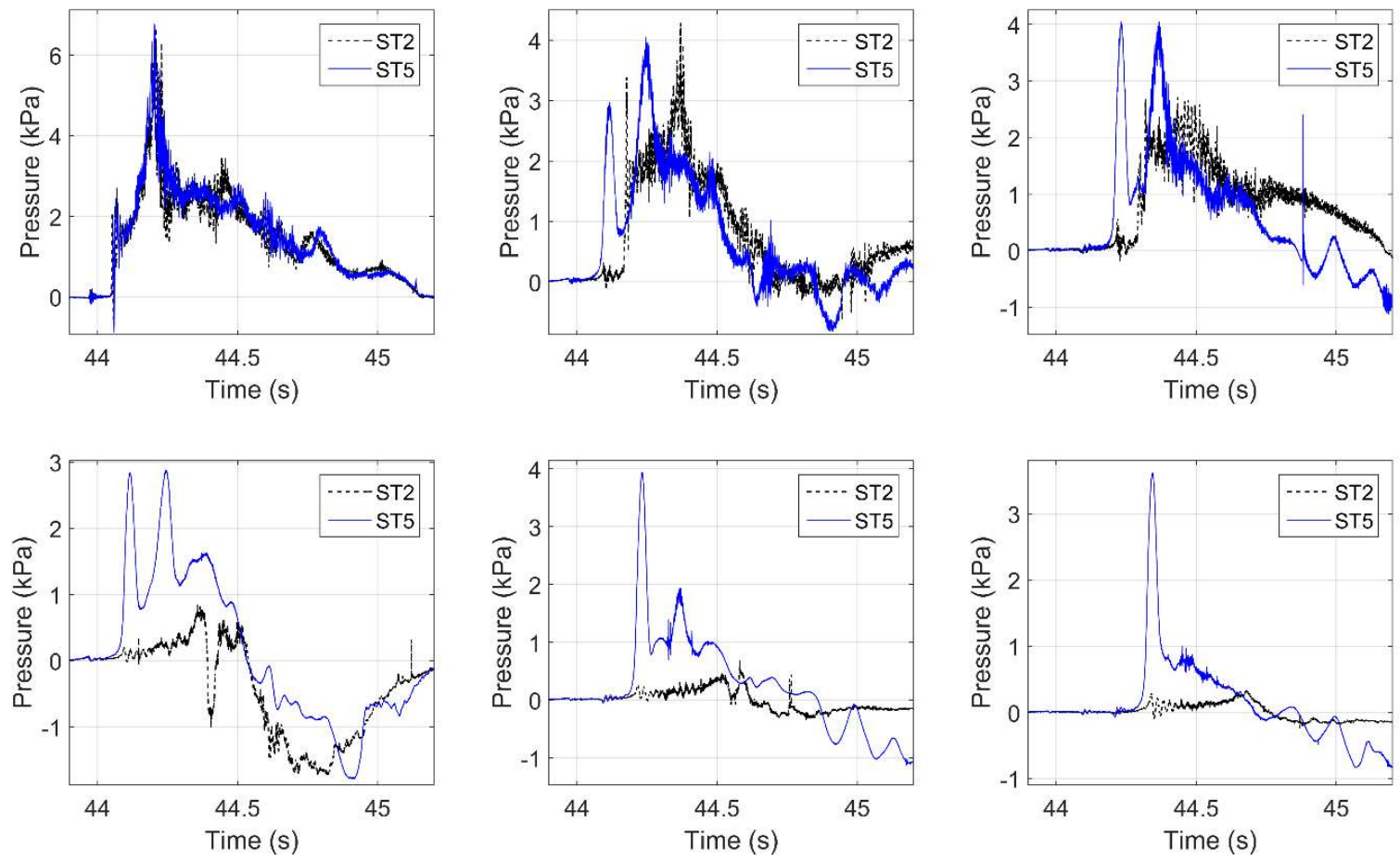

Figure 6. Applied wave pressures on the offshore side of girders (top) G1 (left), G2 (middle), and G3 (right); and below the deck (bottom) in chambers Ch1 (left), Ch2 (middle), and Ch3 (right) for a solitary wave with $\mathrm{H}=0.42 \mathrm{~m}$ and two deck types.

Although the air-entrapment tends to have a clear, consistent, and significant effect on the pressures applied by solitary waves, this is not the case for turbulent bores, as shown in Figure 7. For bores in particular, the trapped air does not generate two peaks in the pressure histories, indicating that this effect is dependent on the wave type. Moreover, although the air does offset the pressure peaks in time so that they occur faster than in the case without air, this shifting is not as significant as in the case of solitary waves. Another noticeable difference is the fact that for bores the trapped air does not always smooth out the pressures and does not have a consistent effect on the magnitude of the pressure peaks, which can either increase or decrease. This variable effect might be due to the fact that the trapped air interacts differently with different turbulent bores, resulting in a complex nonlinear wave-air interaction phenomenon, which modifies the wave flow and the applied pressures. This figure reveals the existence of a more complex temporal interaction between the air and the tsunami-like bores, than in the case of simplified solitary waves, and further investigation is needed for deciphering this interaction.

Figure 8 shows the maximum recorded pressures on the interior girders G2 and G3 and below the deck in chambers 1 and 2 for all tested wave heights at a $2 \mathrm{~m}$ water depth. In these graphs the bores correspond to nominal wave heights starting from $0.80 \mathrm{~m}$ and larger. It must be noted that, although in the time-histories of the previous section, the air-entrapment increased the pressure in the middle 
chamber by a factor of about 3 for a $0.42 \mathrm{~m}$ wave height, this is not true for all heights and the effect is not the same in all chambers and girders. For example, in the middle chamber (Ch2) the pressures for all the wave heights, apart from the $0.70 \mathrm{~m}$ and $0.90 \mathrm{~m}$, show an increase due to the trapped air; however, this trend is not the same in the offshore chamber (Ch1), where the air has a variable effect for different wave heights.
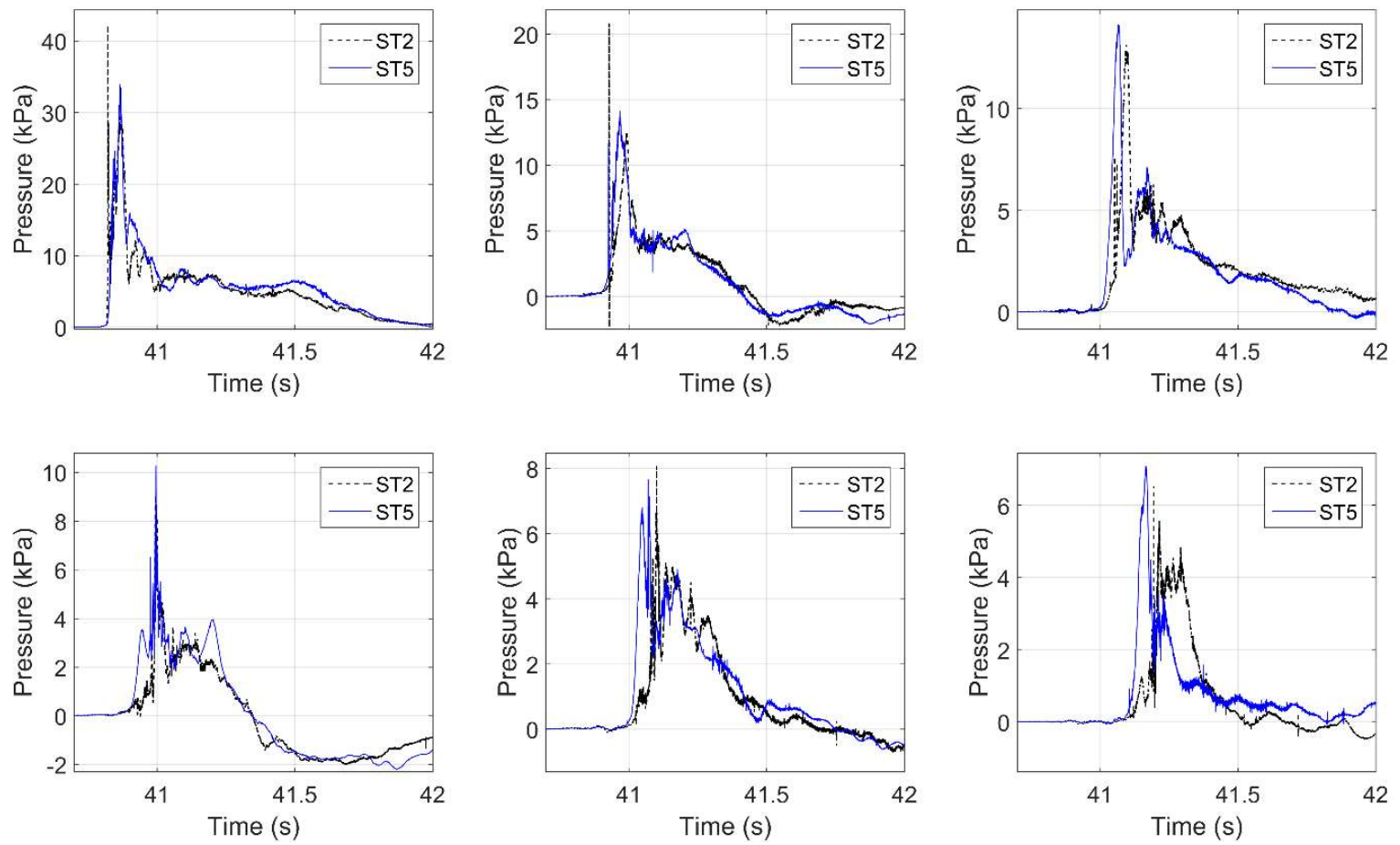

Figure 7. Applied wave pressures on the offshore side of girders (top) G1 (left), G2 (middle), and G3 (right); and below the deck (bottom) in chambers Ch1 (left), Ch2 (middle), and Ch3 (right) for a bore with $\mathrm{H}=0.42 \mathrm{~m}$ and two deck types.

This complex effect can be witnessed on the girder pressures too, with the trapped air reducing the pressures on girder G2 and slightly increasing the ones on G3 for most waves. The fact that the trapped air has a different effect on the pressures of consecutive chambers and girders, could indicate that the wave is being affected after the complex interaction with the air in the first chamber, resulting in the modification of the flow and the induced pressures on the rest of the chambers. Moreover, the fact that the trapped air does not consistently increase the uplift pressures in all chambers indicates that the applied pressures are not purely hydrostatic ones but there is a significant hydrodynamic component that is influenced by the presence of the air.

In general, as shown in Table 3, the ratios of maximum pressures recorded in ST5 to the respective values in ST2, for all tested wave heights, was between 0.57 and 1.55 for girder G2, and 0.49 and 1.93 for girder G3, 0.42 and 10.65 for chamber 1, and 0.54 and 16.8 for chamber 2, with the mean values at the four locations being $0.96,1.19,2.35$, and 3.52 , respectively. The above ratios demonstrate that the trapped air can increase the pressures below the deck by up to a factor of 16.8 (for Ch2), which is significantly more than the increase of the pressures on the girders. Detailed analysis of the experimental data revealed that the maximum increase of the pressures below the deck occurs for the smallest wave heights, for which the wave cannot reach the bottom of the bridge deck directly or it barely reaches it with reduced energy (e.g., $\mathrm{H}=0.42 \mathrm{~m}$ in Figure 8), and the pressure is applied and transferred to the deck through the compression of the trapped air. It could be argued that for these waves it is expected that the impulsive component of the pressure generated by the vertical velocity of the wave particles is small and while the hydrostatic component (additional buoyancy generated by the trapped air) is the governing one. Therefore, when the air is allowed to escape from 
the sides, as in the case of the deck with cross-frames, the hydrostatic pressure drops and the wave itself applies negligible upwards pressure on the deck. If the three smallest wave heights $(H=0.36$, 0.42 , and $0.46 \mathrm{~m}$ ), which are the outliers, are removed then the maximum ratios of pressures recorded in ST5 to the respective values in ST2 are reduced significantly, from 10.65 to 3.36 for chamber 1, 16.8 to 3.78 for chamber 2, and the mean values are reduced from 2.35 to 1.16 and from 3.53 to 1.60 for the two chambers, respectively. On the other hand, the removal of the outliers has a minor effect on the ratios of the pressures on the girders.
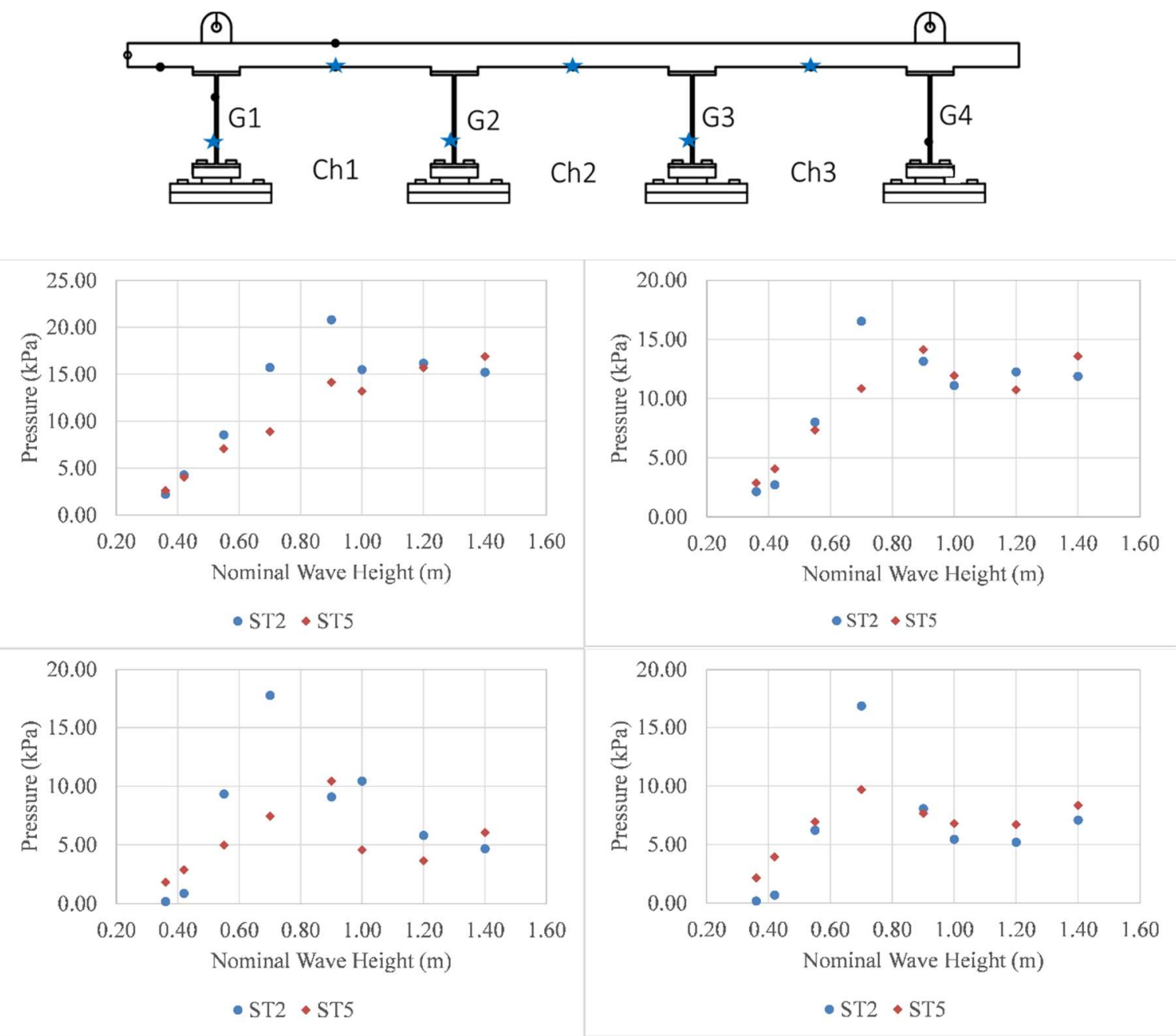

Figure 8. Maximum recorded pressures on girders G2 (top-left) and G3 (top-right), and below the deck in chambers Ch1 (bottom-left) and Ch2 (bottom-right), for all tested wave heights at a $2.0 \mathrm{~m}$ water depth and two deck types.

Table 3. Ratios of maximum pressures measured on the girders G2 and G3 and below the deck in chambers 1 and 2, of the bridge deck with solid diaphragms (ST5) to the maximum values of the deck with cross-frames (ST2).

\begin{tabular}{ccccccccc}
\hline & \multicolumn{3}{c}{ All Tested Wave Heights } & \multicolumn{3}{c}{ Three Smallest Wave Heights Removed } \\
\cline { 2 - 9 } & Girder2 & Girder3 & Chamb.1 & Chamb.2 & Girder2 & Girder3 & Chamb.1 & Chamb.2 \\
\hline Max & 1.55 & 1.93 & 10.65 & 16.8 & 1.55 & 1.93 & 3.36 & 3.78 \\
Min & 0.57 & 0.49 & 0.42 & 0.54 & 0.57 & 0.49 & 0.42 & 0.54 \\
Mean & 0.96 & 1.19 & 2.35 & 3.53 & 0.94 & 1.10 & 1.16 & 1.6 \\
\hline
\end{tabular}




\subsection{Total Forces and Moments}

Figure 9 presents the time histories of the total horizontal forces recorded in the links, total vertical forces and overturning moments, together with the fast Fourier transforms (FFTs) of the total vertical forces, for three selected wave heights. Inspection of the graphs reveals that the deck types have no significant difference in the maximum horizontal forces, because for all bores and several solitary waves the maximum value occurs at the time of the initial impact-in Phase 1 - where the trapped air has no effect; however, as the wave inundation progresses, the air and the wave-air interaction seem to alter the force history by smoothing some of the peaks. Regarding the vertical forces, the air entrapment in the bridge with diaphragms has a more significant effect than on the horizontal forces, by increasing the duration and magnitude of most uplift peaks observed in the time-histories. In fact, for the smallest wave of Figure $9(\mathrm{H}=0.42 \mathrm{~m})$ the trapped air increases the maximum uplift by $73 \%$. However, this effect is not consistent for the whole vertical force histories, with the trapped air tending to have a negligible effect on the first uplift peak, which occurs for most wave heights when the wave hits the offshore overhang and girder (phase 1) and the impulsive forces are maximized. This effect was a characteristic of the bores, but not the solitary waves, which saw an increase even in the first uplift peak due to the air-entrapment.

Interestingly, the trapped air also tends to increase the maximum overturning moment (OTM) for most waves, which was unexpected since, in the deck with cross-frames, the OTM was maximized in phase 1, which is not affected by the presence of the air. However, when the air is trapped in the offshore chamber (Ch1), the clockwise moment at the end of phase 1 (after reaching its maximum value) does not drop quickly to zero, as in the case of the deck with cross-frames, but it keeps increasing due to the uplift pressures on the trapped air of Ch1, causing an increase in the magnitude and overall duration of the maximum clockwise moment (maxOTM). For some bore heights the effect on maxOTM (first peak) is negligible (e.g., $\mathrm{H}=0.90 \mathrm{~m}$ in Figure 9); however, even in this case the moment histories are significantly altered indicating a different wave-structure interaction pattern and structural response. Last but not least, the bottom graphs of Figure 9 demonstrate that the trapped air, which was seen to smooth out some of the forces peaks and increase their duration in the time-histories, reduced the main frequency that governs the solitary wave-induced forces. For bores, this shifting was not significant or consistent as in the case of solitary waves, which agrees with the trends seen in the pressure histories.

To obtain an overview of the role of trapped air, Figure 10 plots the maximum recorded uplift forces and clockwise moments for all wave heights (both solitary waves and bores) tested for a $2.0 \mathrm{~m}$ water depth. Interestingly, although the air entrapment does not have a consistent effect on the pressures measured at aforementioned locations below the deck, it does have a consistent effect on the total uplift forces by tending to increase them for both solitary waves and bores. However, the exact amount of increase in the uplift forces depends on the wave height. For some heights the increase can be negligible, while for others it can be significant, with the air-entrapment causing an increase of the uplift force by $39 \%$ on average, $2 \%$ minimum, and $148 \%$ maximum. The largest increase was witnessed for the smaller solitary wave heights, which is reasonable because when the air is absent these waves can barely apply any direct slamming pressures and uplift forces on the deck, while when air is trapped then the buoyancy force increases significantly governing, consequently, the uplift forces. For example, for $\mathrm{H}=0.36 \mathrm{~m}$ the maximum uplift increases by a factor of 2.48 . On the other hand, some wave heights (both solitary waves and bores) showed a very small increase in the total uplift forces such as the $0.46,0.65$, and $1.0 \mathrm{~m}$ waves $($ at $\mathrm{d}=1.90 \mathrm{~m})$ and the $0.70 \mathrm{~m}$ wave $(\mathrm{at} \mathrm{d}=2.0 \mathrm{~m})$, and this could be attributed to the fact that:

1. For both bridge specimens for certain waves the maximum uplift force occurs in Phase 1, where the slamming (impulsive) force on the overhang is governing and the air trapped in the chambers is not affecting the results (true for $\mathrm{H}=0.46 \mathrm{~m}$ ); 
2. For other waves the maximum uplift for ST2 occurs in Phase 1, while for ST5 it occurs in Phase 3 (true for $\mathrm{H}=1.0 \mathrm{~m}, \mathrm{~d}=1.90 \mathrm{~m}$ ) where the quasi-static component is governing, making it hard to decipher the underlying physics by just examining the maximum values of the uplift force.

Regarding the maximum clockwise moment (maxOTM), the deck with diaphragms (ST5) seems to witness increased moments relative to the one with cross-frames (ST2) for the majority of the tested wave heights. However, there were a few heights (e.g., $\mathrm{H}=0.90$ and $1.10 \mathrm{~m}$ ) for which there was a negligible difference or even a slight decrease of maxOTM. In particular, the ratios of maxOTM recorded on the deck with diaphragms to the one with cross-frames had a mean value of 1.32 and a maximum value of 3.12, with the latter one occurring for the smallest wave height $(\mathrm{H}=0.36 \mathrm{~m})$. Overall the trapped air tends to increase both the maximum uplift forces (maxFup) and the maximum overturning moment (maxOTM) with the largest effect on the former parameter, while altering the time-histories and temporal variation of both. However, this effect is not consistent for all wave heights and wave types, a fact that demonstrates the complexity of the role of air on the wave-structure interaction and induced effects on structures with complex geometries such as decks with open-girders. To decipher the underlying physics of these complex phenomena further investigation is needed.

(a)
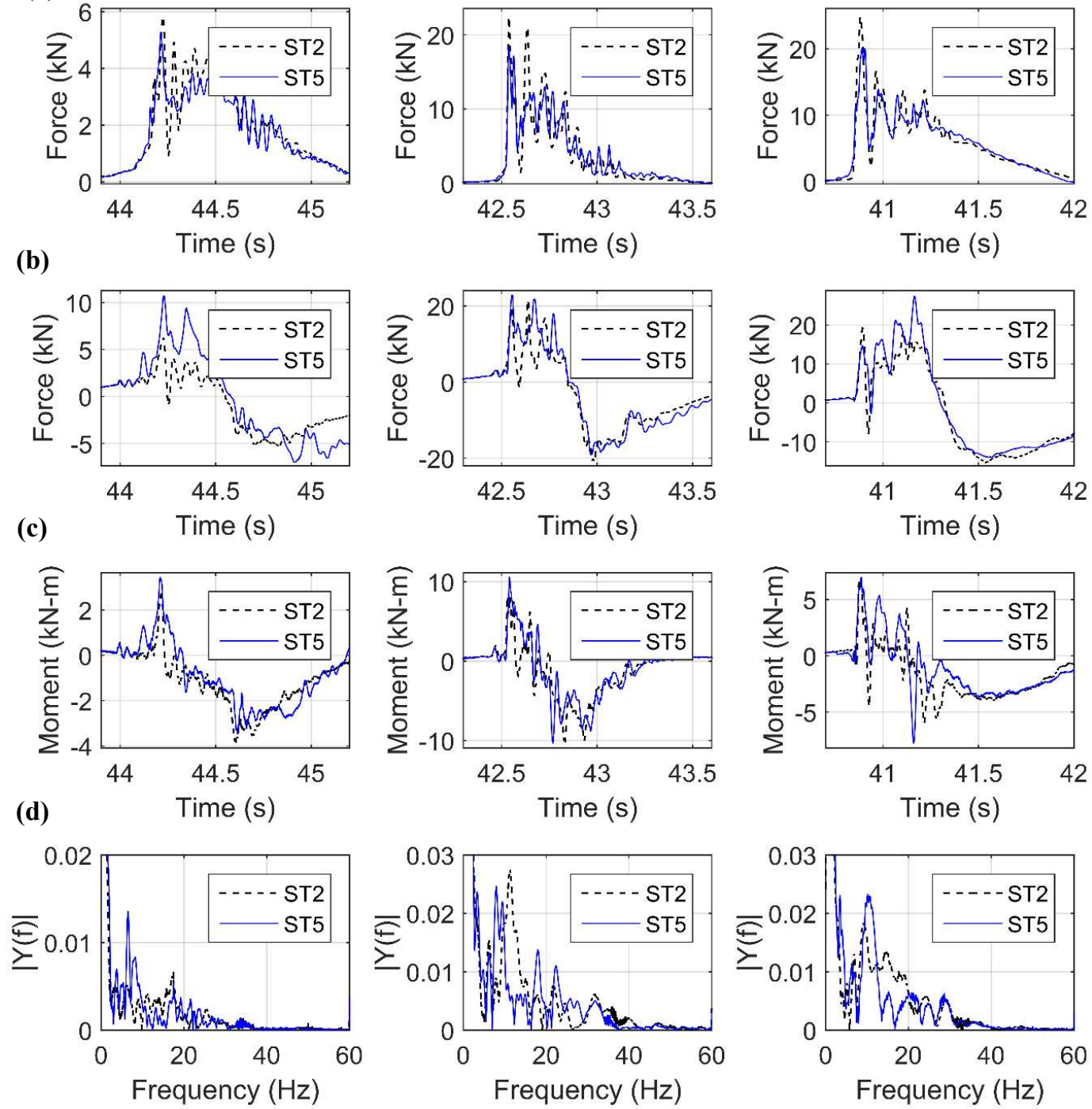

Figure 9. Time histories of (a) total horizontal forces, (b) total vertical forces, and (c) moments, and (d) FFTs of the total vertical forces, for three waves with $\mathrm{H}=0.42 \mathrm{~m}$ (left), $\mathrm{H}=0.65$ (middle), and $\mathrm{H}=0.90 \mathrm{~m}$ (right), and two deck types (FFT = Fast Fourier Transform). 

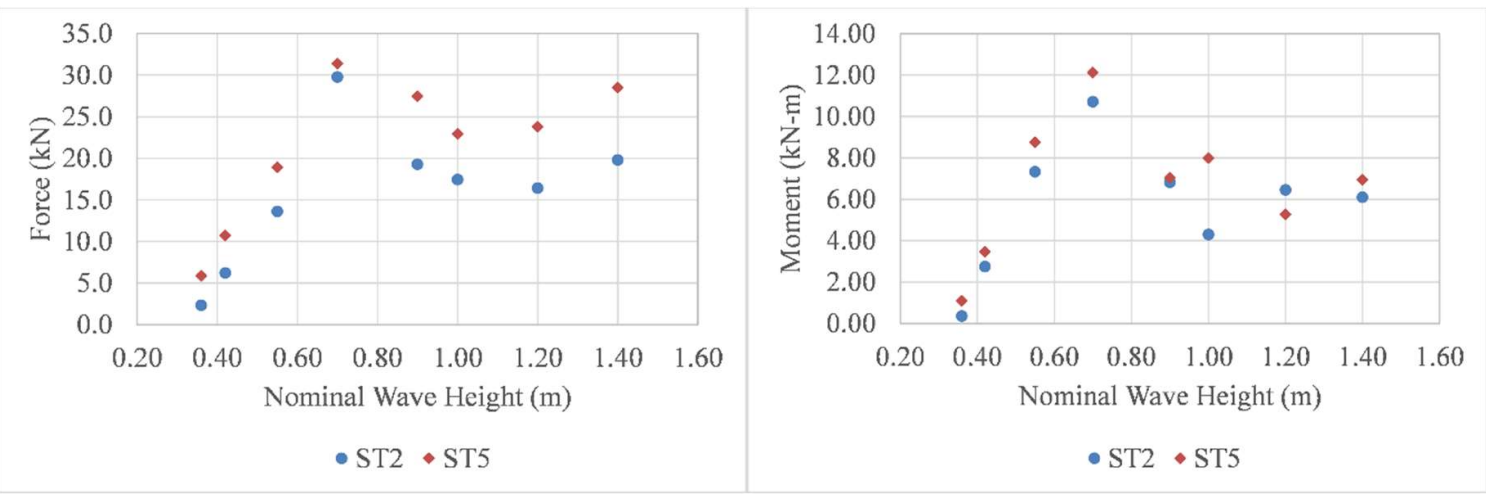

Figure 10. Max recorded uplift forces (left) and overturning moments (right), for the two deck types and all the heights tested at $\mathrm{d}=2.0 \mathrm{~m}$.

Figure 11 shows the time histories of vertical forces and pressures below the deck, which are normalized with their respective maximum values, for the two deck types and three wave heights. The first two heights $(\mathrm{H}=0.42$ and $0.65 \mathrm{~m})$ correspond to solitary waves and the last one to a bore. As explained in previous sections, for the deck with cross-frames (ST2), there were three different uplift phases, with the first one corresponding to the impact of the wave below the offshore overhang that generated an impulsive uplift peak, and the two other phases corresponding to the impact of the wave below the deck in the chambers, which generated a longer duration uplift with local peaks each time that the wave reached a chamber. Figure 11 reveals that the presence of the trapped air has a totally different effect when the deck is inundated by solitary waves or by bores. For solitary waves, the air modifies the vertical force pattern and phases so that after the impact below the offshore overhang and the occurrence of the impulsive uplift peak, the uplift does not immediately drop to zero or negative values (downward), but it keeps increasing both in magnitude and duration. The reason behind this behavior is the fact that although the crest of the wave is still at the location of the overhang, the tip of the wave has already reached chamber 1 (Ch1) and has started to apply pressures on the trapped air generating a buoyancy force in Ch1. As a result, before the slamming uplift force applied below the overhang is zeroed, the hydrostatic force in Ch1 starts increasing, which leads to a longer duration uplift. This in turn modifies the vertical forces histories and the phases defined for the bridge with cross-frames, by merging the two uplift peaks of the overhang (phase 1) and Ch1 (phase 2) into one peak, making it harder to distinguish the transition from phase 1 to phase 2 .

On the other hand, for bores there is no significant effect on the impulsive uplift peak of phase 1. The trapped air tends to alter mainly the pattern and magnitudes of the uplift forces in phases 2 and 3 , which occur when the waves is flooding the chambers. This is a fundamental difference between the two wave types, indicating the earlier findings on the role of trapped air during the wave impact on elevated decks, might not be directly applicable to tsunami-like bores.

\subsection{Slamming and Quasi-Static Forces}

To improve the understanding of the physics involved, the total forces measured in the experiments were analyzed using the empirical mode decomposition method (EMD) (Huang 1999 [37]) and the Frequency Response Function (FRF) method, and both methods yielded similar slamming and quasi-static force components. The EMD method has been used in previous studies for decomposing the total forces of breaking waves on offshore structures. In this study, the approach presented by Jose et al. [36] is implemented. In the first step of the method the total forces are filtered to remove noise in the signal. In the second step, the EMD method is applied and the first intrinsic mode with the residue is obtained, representing the amplified component (due to the structural response) and the net force, respectively. In the last step, the net breaking force is separated into a slamming and a quasi-static via a low-pass filter. The two components of the horizontal and vertical forces of a selected bore 
are shown in Figure 12. Notably, the maximum slamming and maximum quasi-static loads occur at different time instants, which is consistent with previous studies [38].
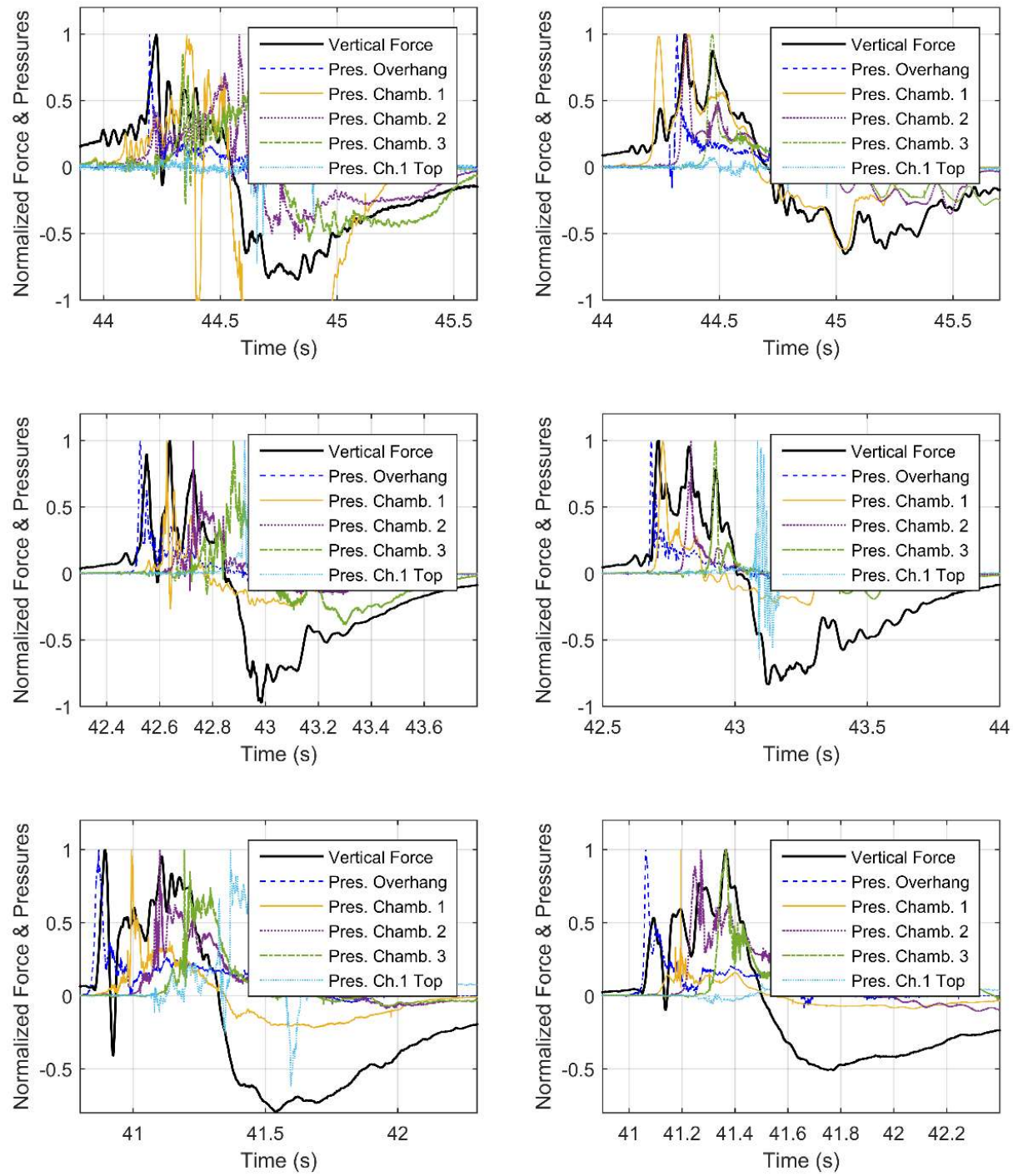

Figure 11. Time histories of normalized vertical forces and pressures below the deck for a deck with cross-frames (left) and with solid diaphragms (right) for two solitary waves, with $\mathrm{H}=0.42 \mathrm{~m}$ (top), $\mathrm{H}=0.65 \mathrm{~m}$ (center), and a bore with $\mathrm{H}=0.92 \mathrm{~m}$ (bottom).
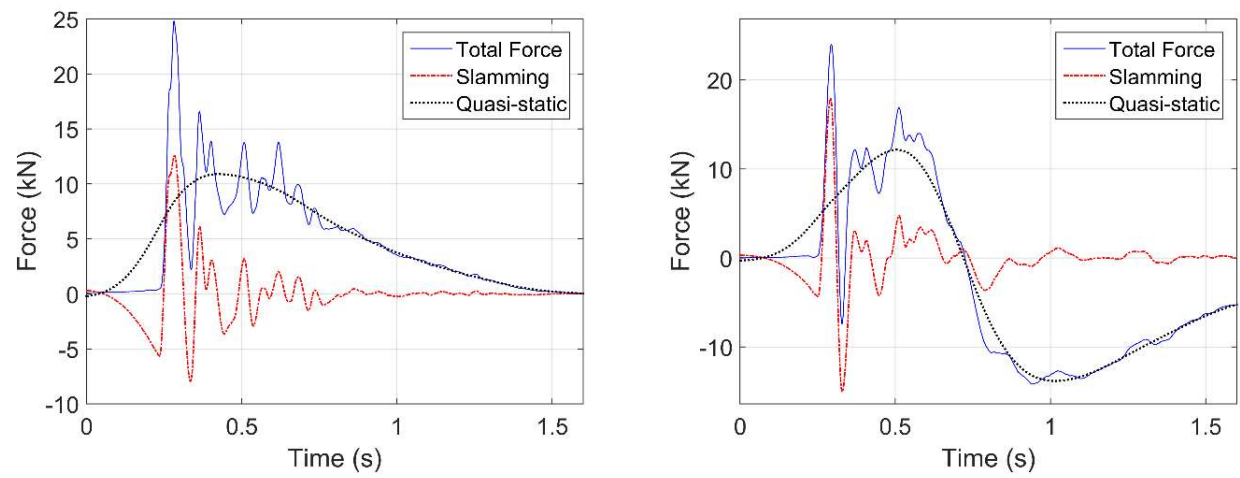

Figure 12. Total, slamming, and quasi-static force histories in the horizontal (left) and vertical direction (right), obtained via the empirical mode decomposition method, for $\mathrm{H}=0.90 \mathrm{~m}$. 
Using the results from the EMD method, Figure 13 presents the slamming and quasi-static vertical forces for two solitary waves $(\mathrm{H}=0.42$ and $0.55 \mathrm{~m})$ and a bore $(\mathrm{H}=0.90 \mathrm{~m})$, for both deck types. Interestingly, for these wave heights, the two decks seem to be witnessing vertical slamming forces that have similar maximum uplift values, and this can be attributed to the fact that they tend to occur in phase 1, where the trapped air does not have a significant influence. However, this is not the case for all the tested wave heights, with the air having a complex and inconsistent effect on the maximum slamming uplift force, which could either increase or decrease depending on the wave type and wave height. The trapped air had also a significant effect on the temporal variation of the slamming forces by smoothing out the impulsive peaks in the force histories, but not necessarily reducing their magnitude. In fact, the air was seen to increase some uplift peaks that occurred in phases 2 and 3, which was unexpected. However, this could be justified by the complex and dynamic interaction of the trapped air with the wave and especially the bore, which, as discussed earlier in this article, did not necessarily reduce the impulsive uplift pressure peaks and their high-frequency (measured at specific locations of the deck). Therefore, the inconsistent effect of the trapped air on the applied pressures seems to have been transferred also to the slamming component of the uplift forces.
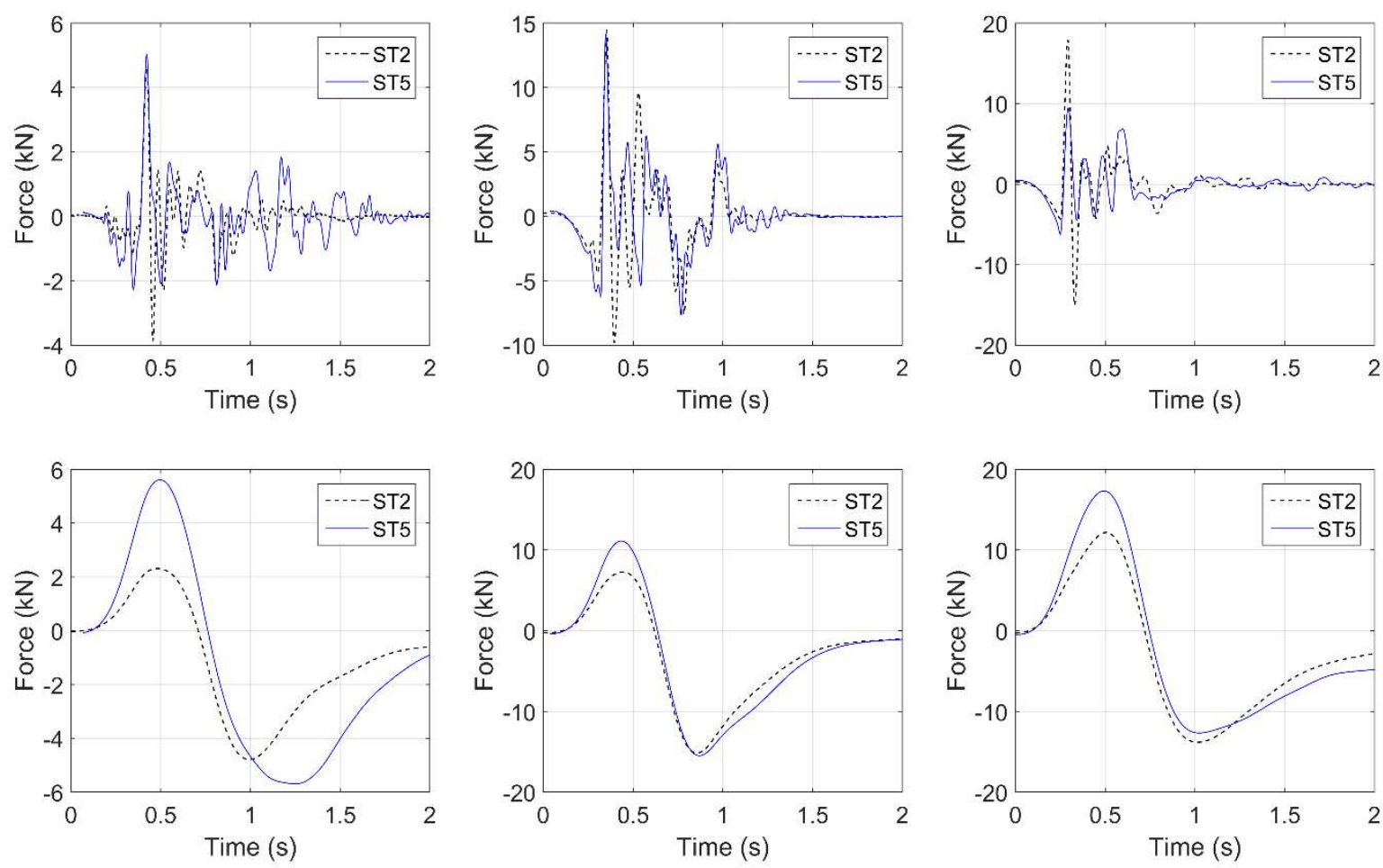

Figure 13. Time-histories of slamming and quasi-static total vertical forces, for two deck types and two waves with $\mathrm{H}=0.42 \mathrm{~m}, \mathrm{H}=0.55 \mathrm{~m}$, and $\mathrm{H}=0.90 \mathrm{~m}$.

Despite the unclear effect on the slamming forces, the air-entrapment has a consistent effect on the quasi-static component of the uplift force by increasing its magnitude for both wave types and all wave heights. For some heights it also modifies the solitary wave as it propagates through the chambers, resulting in an increase of the duration of the bridge inundation and the quasi-static uplift force. Table 4 shows a comparison of the maximum total and quasi-static uplift forces introduced in the two deck types (below the bent cap). It becomes evident that the trapped air increases the maximum values of quasi-static forces, by at least $30 \%$ for most waves (apart from $\mathrm{H}=0.70 \mathrm{~m}$ in which case it was $13 \%$ ) and up to $142 \%$, with the largest increase occurring for the smallest wave $(\mathrm{H}=0.36 \mathrm{~m})$. Interestingly, although the air-entrapment is always resulting in an increase of the quasi-static force, this is not always translated into an increase in the maximum total force, as shown in the table. Two possible reasons for the observed behavior are the facts that: 
- The maximum total uplift force can occur in any of the three uplift phases, so when this happens in phase 1 , then there is practically no effect from the trapped air. The quasi-static uplift component is maximized though in either phase 2 or 3 , which occur when the wave floods the chambers and, consequently, the induced uplift is affected by the trapped air.

- The maximum total uplift force is affected by the slamming and the quasi-static components, which are maximized at different instants of the bridge inundation process. Moreover, although the effect of trapped air on the quasi-static component is consistent, this is not true for the slamming component. Therefore, depending on whether the trapped air increases or reduces the slamming uplift peaks and how close they are in time with the maximum quasi-static uplift, which always increases, the air can result in a significant increase of the total uplift or a negligible effect, respectively.

Table 4. Ratios of maximum total uplift forces of the deck with solid diaphragms (ST5) to the maximum values of the deck with cross-frames (ST2).

\begin{tabular}{|c|c|c|c|c|c|c|c|c|c|c|}
\hline \multirow{2}{*}{$\mathrm{H}(\mathrm{m})$} & \multicolumn{2}{|c|}{ Phase of Max Fup } & \multicolumn{4}{|c|}{ Total Uplift Forces Fup } & \multicolumn{4}{|c|}{ Quasi-static Uplift Forces Fup,qs } \\
\hline & ST2 & ST5 & $\begin{array}{l}\mathrm{ST} 2 \\
(\mathrm{kN})\end{array}$ & $\begin{array}{c}\text { ST5 } \\
(\mathrm{kN})\end{array}$ & $\begin{array}{l}\text { ST5/ } \\
\text { ST2 }\end{array}$ & $\begin{array}{l}\text { ST5- } \\
\text { ST2 }\end{array}$ & $\begin{array}{c}\text { ST2 } \\
(\mathrm{kN})\end{array}$ & $\begin{array}{l}\text { ST5 } \\
(\mathrm{kN})\end{array}$ & $\begin{array}{l}\text { ST5/ } \\
\text { ST2 }\end{array}$ & $\begin{array}{l}\text { ST5- } \\
\text { ST2 }\end{array}$ \\
\hline 0.46 & $\mathrm{~A}$ & $\mathrm{~A} / \mathrm{B}$ & 9.02 & 9.18 & 1.02 & 0.16 & 3.15 & 4.94 & 1.57 & 1.79 \\
\hline 0.52 & $\mathrm{~A}$ & $\mathrm{~A} / \mathrm{B}$ & 16.69 & 19.88 & 1.19 & 3.18 & 4.55 & 7.59 & 1.67 & 3.04 \\
\hline 0.65 & B & $\mathrm{A} / \mathrm{B}$ & 21.55 & 22.91 & 1.06 & 1.36 & 9.00 & 13.10 & 1.46 & 4.10 \\
\hline 0.80 & B & B & 7.98 & 12.36 & 1.55 & 4.38 & 6.64 & 8.94 & 1.35 & 2.30 \\
\hline 1.00 & A & B & 10.54 & 10.89 & 1.03 & 0.36 & 6.82 & 9.55 & 1.40 & 2.73 \\
\hline 1.10 & B & B & 9.00 & 13.49 & 1.50 & 4.48 & 7.56 & 10.02 & 1.32 & 2.46 \\
\hline 1.30 & A & B & 11.34 & 15.52 & 1.37 & 4.18 & 6.24 & 12.26 & 1.97 & 6.03 \\
\hline 0.36 & B & B & 2.37 & 5.87 & 2.48 & 3.50 & 1.62 & 3.93 & 2.42 & 2.30 \\
\hline 0.42 & A & $\mathrm{A} / \mathrm{B}$ & 6.13 & 10.74 & 1.75 & 4.61 & 2.97 & 6.52 & 2.19 & 3.55 \\
\hline 0.55 & A & B & 13.45 & 18.93 & 1.41 & 5.48 & 9.33 & 12.93 & 1.39 & 3.60 \\
\hline 0.70 & B & B & 30.25 & 31.39 & 1.04 & 1.14 & 17.87 & 20.16 & 1.13 & 2.29 \\
\hline 0.90 & A & B & 19.29 & 27.48 & 1.42 & 8.19 & 12.81 & 16.97 & 1.32 & 4.16 \\
\hline 1.00 & B & B & 17.48 & 22.95 & 1.31 & 5.47 & 12.44 & 16.62 & 1.34 & 4.18 \\
\hline 1.20 & $A, B$ & B & 17.55 & 23.79 & 1.36 & 6.25 & 12.19 & 16.98 & 1.39 & 4.78 \\
\hline \multirow[t]{4}{*}{1.40} & $\mathrm{~A}, \mathrm{~B}$ & B & 19.88 & 28.49 & 1.43 & 8.61 & 14.50 & 18.83 & 1.30 & 4.33 \\
\hline & & & & Mean & 1.39 & 4.09 & - & - & 1.55 & 3.44 \\
\hline & & & & SD & 0.36 & 2.49 & - & - & 0.35 & 1.13 \\
\hline & & & & $\mathrm{CV}$ & $26 \%$ & $61 \%$ & - & - & $23 \%$ & $33 \%$ \\
\hline
\end{tabular}

In order to advance the understanding of the role of trapped air further, Table 4 presents also the phase in which the maximum uplift (maxFup) takes place for each deck type. Phase A corresponds to the impulsive uplift (phase 1), while phase B corresponds to the longer duration uplift (phases 2 and 3). Additionally, the symbol " $\mathrm{A}, \mathrm{B}$ " means that the maximum uplift can occur in either of these phases, while the symbol " $\mathrm{A} / \mathrm{B}$ " means that the maximum occurs during the transition from phase 1 to phase 2, which, as explained in the previous section, is significantly altered when trapped air is present and the wave is impacted by a solitary wave. Examination of the phases of maxFup for ST2 and ST5 verifies the argument made earlier that for many waves the maximum uplift does not occur at the same instant and not even in the same phase for both deck types, meaning that the comparison of the magnitudes does not tell the whole story since it does not capture the complex temporal variation of the wave-induced forces.

Last but not least, the comparison of the total and quasi-static uplift forces for the wave heights that both bridge types witness the maximum uplift in Phase B, and particularly the columns of Table 4 that show the difference of the uplift forces (ST5-ST2), reveals that the air-entrapment has a fundamentally different effect for solitary waves and bores. Interestingly, for all bores (apart from one height) the 
trapped air increases both the quasi-static and total uplift force; however, the absolute increase of the total force is significantly more than the quasi-static one, indicating that the rest of the increase comes from the change of the hydrodynamic component. On the other hand, for the solitary waves the increase of the total force can be either smaller (e.g., $\mathrm{H}=0.70 \mathrm{~m}$ ) or larger (e.g., $\mathrm{H}=0.36 \mathrm{~m}$ ) than the quasi-static component, demonstrating that for such waves the trapped air always increases the quasi-static force, but can either decrease or increase the hydrodynamic force component in Phase B. The increase of the uplift force due to the air-entrapment has been also observed by other small-scale experimental studies of solitary waves impacting bridge decks (e.g., [8]) and the present study demonstrates that this increase comes mainly from the increase of the quasi-static component.

One of the most valuable findings emerging from this section is that the exact effect of the trapped air depends on the type of wave-solitary wave or bore-that inundates the bridge, which has not been discussed in the literature to date. Solitary waves have a different wave shape than bores, are more stable, have more uniform particle velocities, and they move as big volumes of water that trap the air in the chamber all together. On the other hand, bores do not have a stable wave shape, have very variable particle velocities, and a turbulent mixture of air and water particles, each of which interacts differently with the trapped air in the chambers, causing a more variable compression of the trapped air and leading to a fundamentally different wave-air-structure interaction.

\subsection{Vertical Forces in Bearings and Columns}

Given the fact that for the largest percentage of damaged bridges in recent tsunamis the failure occurred in the bearings or bearing connections and in few cases in the columns, it is critical to quantify the forces that these components have to withstand, and understand how they are affected by the air-entrapment. To this end, Table 5 presents the maximum values of the total deck uplift (Fup), overturning moment (OTM), and uplift forces in individual bearings and columns. Note that for a few wave heights the uplift forces in the bearings are missing and this is due to a technical issue with the data acquisition system. Surprisingly, it can be observed that the air-entrapment associated with the bridge with diaphragms does not increase the uplift forces neither in the bearings of girders G1, G2, and G3 nor in the offshore columns for many of the tested wave heights, although the total deck uplift increases for the same waves. In fact, for some heights (e.g., $\mathrm{H}=0.90,1.10,1.20$, etc.) the deck uplift increases significantly (e.g., by up to $50 \%$ ), while the maximum uplift in the offshore bearings and columns decreases by up to $18 \%$ and $16 \%$, respectively, which seems counter-intuitive. On the other hand, for other wave heights (e.g., $\mathrm{H}=0.70$ and $1.00 \mathrm{~m}$ ) the uplift demand in the bearings and columns offshore of the C.G. of the deck increase more than the increase of the total deck uplift. This means that the current approach of investigating the effect of trapped air only on the total uplift force cannot sufficiently describe the induced effects on the structural components that are essential for the survival of the bridge.

A possible explanation for the above observed behavior is the fact the uplift in the offshore members and connections of an elevated deck tends to be maximized when the clockwise overturning moment is maximized and not necessarily when the deck uplift is maximized. This seems to be, indeed, the explanation for some of the aforementioned wave heights that introduced a reduced uplift demand in individual offshore connections, such as the $1.10 \mathrm{~m}$ wave, which applied a reduced OTM on the deck with solid diaphragms. However, even the maximum moment itself still cannot explain the observed behavior for all waves, since there were waves for which the trapped air introduced both increased deck uplift and increased OTM, but reduced uplift forces in the offshore bearings and columns. This finding demonstrates the complexity of the effect of air-entrapment on the uplift forces of the offshore structural components, which cannot be captured only via examination of the total deck uplift, as done in previous studies.

On the other hand, the uplift forces in the onshore columns and bearings tend to have a more consistent trend and are significantly increased by the air-entrapment. In particular, the increase of the forces in the onshore columns ranges between $8 \%$ and $292 \%$, with a mean value of $105 \%$ among the 
tested waves. The different effect of the air on the onshore columns/bearings relative to the offshore ones can be attributed to the fact that the forces in the former components can be maximized in any of the first two phases (1 or 2), with the air-entrapment having a different effect in each phase, while the forces in the onshore components are always maximized in phase 3 , where the quasi-static force is large and is consistently increased by the trapped air. Generally, as shown in Table 5, the role of trapped air becomes more consistent in increasing the uplift demand as we are moving from the offshore to the onshore connections, with the mean ratio of the demand in ST5 to the one in ST2 being 1.02, 1.07, 1.19 , and 1.53 for bearings G1, G2, G3, and G4, respectively, and 1.13, 1.45, and 2.05 for columns 1, 2, and 3 , respectively.

Table 5. Ratios of maximum total uplift forces, moments, and uplift forces in individual bearings and columns of the deck with solid diaphragms to the respective values of the deck with cross-frames.

\begin{tabular}{cccccccccc}
\hline H $(\mathbf{m})$ & Total Fup & OTM & Brgs, G1 & Brgs, G2 & Brgs, G3 & Brgs, G4 & Col. 1 & Col. 2 & Col. 3 \\
\hline 0.46 & 1.02 & 0.96 & 0.98 & 1.02 & 1.24 & 1.29 & 0.98 & 1.39 & 1.89 \\
0.52 & 1.19 & 1.06 & - & - & - & - & 0.97 & 1.42 & 1.50 \\
0.65 & 1.06 & 1.30 & 1.08 & 1.15 & 1.14 & 1.54 & 1.04 & 1.20 & 1.72 \\
0.80 & 1.55 & 1.76 & 1.51 & 1.56 & 1.77 & 1.29 & 1.51 & 2.00 & 2.51 \\
1.00 & 1.03 & 1.28 & 0.85 & 0.88 & 0.89 & 1.06 & 0.90 & 1.17 & 1.90 \\
1.10 & 1.50 & 0.87 & 0.82 & 0.94 & 1.19 & 1.33 & 0.84 & 1.23 & 1.94 \\
1.30 & 1.37 & 1.05 & 0.90 & 0.92 & 0.97 & 1.64 & 0.91 & 1.15 & 2.61 \\
0.36 & 2.48 & 3.12 & - & - & - & - & 2.11 & 2.51 & 3.20 \\
0.42 & 1.75 & 1.26 & 1.25 & 1.42 & 1.72 & 2.91 & 1.22 & 1.64 & 3.92 \\
0.55 & 1.41 & 1.20 & - & - & - & - & 1.02 & 1.38 & 1.57 \\
0.70 & 1.04 & 1.13 & 1.16 & 1.12 & 0.99 & 0.61 & 1.11 & 1.08 & 1.08 \\
0.90 & 1.42 & 1.03 & 0.84 & 0.85 & 1.04 & 2.22 & 0.84 & 0.96 & 2.33 \\
1.00 & 1.31 & 1.86 & - & - & - & - & 1.60 & 2.27 & 1.24 \\
1.20 & 1.36 & 0.82 & 0.81 & 0.86 & 0.99 & 1.17 & 0.87 & 1.01 & 1.52 \\
1.40 & 1.46 & 1.14 & 1.09 & 1.11 & 1.20 & 1.75 & 1.07 & 1.29 & 1.77 \\
Mean & 1.39 & 1.32 & 1.02 & 1.07 & 1.19 & 1.53 & 1.13 & 1.45 & 2.05 \\
\hline
\end{tabular}

Similarly to the onshore columns of the bridges, the onshore bearings are the ones that are being affected the most by the air-entrapment and can witness an increase of $53 \%$ on average (among the tested wave heights) and up to $191 \%$. Although, the trapped air seems to cause a consistently significant increase in the forces of the onshore columns, this is not exactly the case for the forces in the onshore bearings, which for the largest solitary wave with $\mathrm{H}=0.70 \mathrm{~m}$ surprisingly decreased by $39 \%$. Therefore, deciphering the effect of the air-entrapment on the forces of the bearings is more challenging than the effect on the columns, because the existence of the shear keys introduces a more complex structural response as the wave inundates the bridge. In particular, the frictional contact between the onshore (and offshore) girder and the respective shear keys, can transfer part of the vertical wave load to the substructure directly via the shear keys affecting, consequently, the vertical forces going into the bearings and the wave-structure interaction.

Figure 14 plots the recorded vertical forces in the individual bearings together with the total vertical force for two selected waves. This figure demonstrates that both bridge types are witnessing similar patterns in the distributions of the forces in the bearings, with the bearings of girders G1 and G2 attracting significantly larger uplift forces than the rest. In fact, for the bridge with cross-frames, the ratio of the maximum uplift force recorded in the offshore bearings (Fup,brngs,G1) to the respective one in the onshore bearings (Fup,brngs,G4) was 9.76 max and 5.17 on average, while for the bridge with diaphragms the respective ratios were 6.0 max and 3.98 average. This is interesting because it demonstrates that the trapped air reduces the ratio of (Fup,brngs,G1/ Fup,brngs,G4) and, as indicated by Table 5 and Figure 14, this happens due to the fact that the air has the biggest effect on the onshore bearings and columns by increasing their maximum uplift force. Moreover, the figure reveals that while the air increases the long duration uplift (phases 2 and 3), this in turn increases parts of the uplift 
force histories in bearings and columns and offsets their maximum value from one phase (e.g., phase 1) to another one (e.g., phase 3). This complex effect on the temporal variation of the uplift demand and the offset of the maximum value could explain the difficulty of deciphering the effect of air on the maximum uplift forces that each structural component has to withstand.
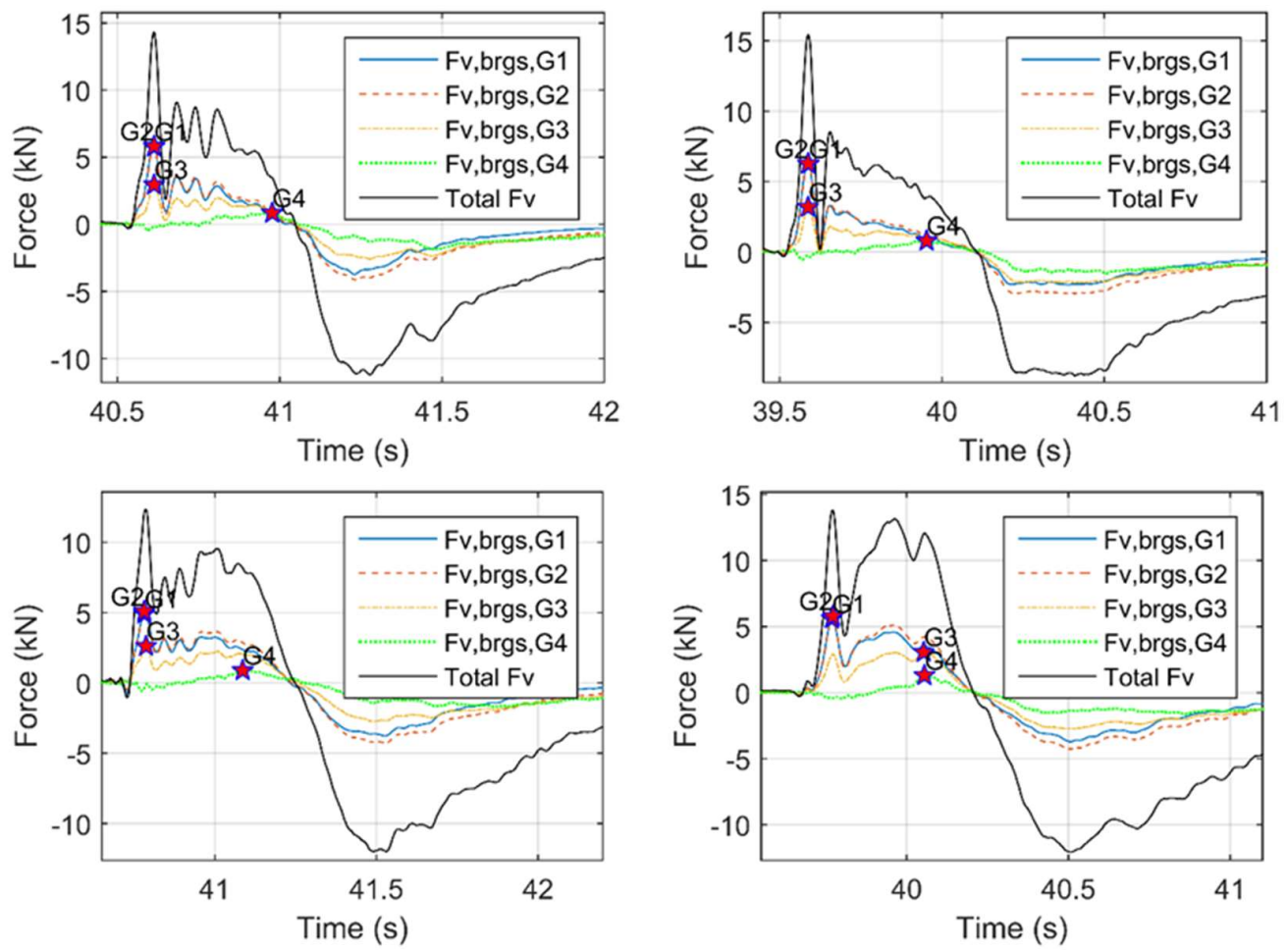

Figure 14. Vertical forces in individual bearings of the deck with cross-frames (top) and the deck with solid diaphragms (bottom), for $\mathrm{H}=1.0 \mathrm{~m}$ (left) and $\mathrm{H}=1.30 \mathrm{~m}$ (right).

The fact that the offshore elastomeric bearings have to withstand the largest uplift forces, while carrying the smallest portion of the counter-acting bridge weight, means that they are more likely to exceed their capacity than the interior bearings, which could lead to a progressive collapse mechanism during the tsunami inundation. Therefore, the designer must ensure that the offshore connections will be strong enough to withstand this increased demand.

\subsection{Structural Response-Deck Rotations}

Previous comparison of pressures, forces, and moments revealed the complex effect of air-entrapment, and indicated that it modifies not only the wave loading but also the wave-structure interaction and structural response. Figure 15, which plots the cumulative rotation (angle $\varphi$ ) for three wave heights, verifies that the above indication is true. For the majority of solitary waves (e.g., $\mathrm{H}=0.42 \mathrm{~m}$ ) in particular, the presence of the air causes a significant increase of the maximum clockwise deck rotation and modifies the time-histories during the three uplift phases. For these waves, both deck types are undergoing significant clockwise rotation as the wave impacts the offshore side of the bridge, which is reduced as the wave starts flooding the chambers, with ST2 witnessing several local peaks/fluctuations, followed by a counter-clockwise rotation until the deck returns to its initial position. For other waves the response is more complicated (e.g., $\mathrm{H}=0.55$ and $0.90 \mathrm{~m}$ ) and is characterized by two distinct cycles of positive angles followed by a negative one. Even for cases that the trapped air does not have an important effect on the maximum clockwise rotation of the deck, it still has a major effect on the temporal variation of the deck rotation and particularly the parts of the time histories corresponding to the inundation of the chambers. 

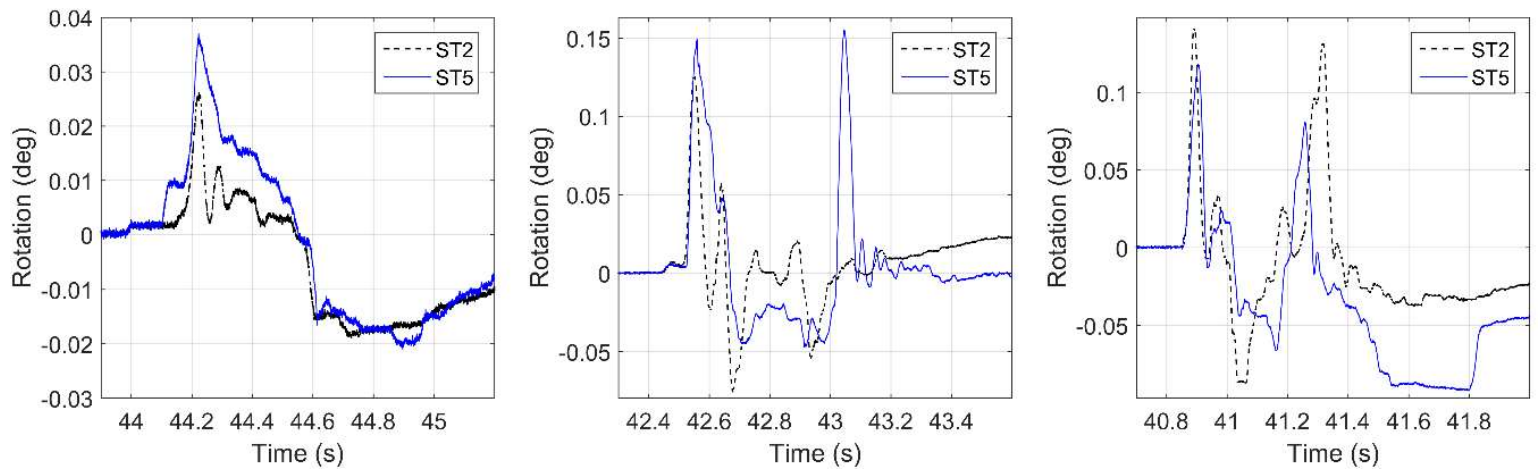

Figure 15. Time histories of cumulative rotation (deck angle), for three waves with $\mathrm{H}=0.42 \mathrm{~m}$ (left), $\mathrm{H}=0.55$ (middle), and $\mathrm{H}=0.90 \mathrm{~m}$ (right), and two deck types.

\section{Measured Uplift Forces vs. Buoyancy}

\subsection{Total Forces vs. Buoyancy}

One of the fundamental differences between a girder bridge with cross-frames and one with diaphragms is that the latter one will trap air underneath the deck, as observed in previous studies [18,38], which will increase the buoyancy force. In order to develop a better understanding of the magnitude of the wave-induced hydrodynamic uplift forces, Figure 16 presents a comparison of the recorded uplift forces with the calculated buoyancy, for both deck types. For the deck with cross-frames, the buoyancy is calculated using the volume of the deck plus the other components (e.g., bearings, connecting plates, etc.), which gives a total of $4.67 \mathrm{kN}$. For the deck with diaphragms, which is expected to trap air but the exact air quantity is unknown, the buoyancy was calculated using the following equations:

$$
\begin{gathered}
\mathrm{F}_{\mathrm{b}, \mathrm{tot}}=\mathrm{F}_{\mathrm{b}, \mathrm{br}}+\mathrm{F}_{\mathrm{b}, \text { air }} \\
\mathrm{F}_{\mathrm{b}, \mathrm{br}}=\gamma \mathrm{V}_{\mathrm{br}} \\
\mathrm{F}_{\mathrm{b}, \text { air }}=\mathrm{n} \gamma \alpha \mathrm{V}_{\mathrm{ch}}
\end{gathered}
$$

where $\gamma=$ unit weight of water, $\mathrm{V}_{\mathrm{br}}=$ volume of the bridge, $\mathrm{n}=$ number of chambers that are assumed to have trapped air, $\mathrm{V}_{\mathrm{ch}}=$ volume of one bridge chamber (created between two consecutive girders and the bottom of the deck, see Figure 1), and $\alpha=$ percentage of the volume of chamber that is filled with air. In this study, two values of $\alpha$ were examined and particularly 0.5 and 1 , which correspond to $50 \%$ and $100 \%$ of air-entrapment, respectively. The $50 \%$ ratio was selected following the recommendation by McPherson [18], who found that, using this assumption and considering the additional buoyancy of the trapped air, the experimental data were estimated relatively well using simplified predictive equations. The $100 \%$ value was selected in order to get an upper bound for the buoyancy of a deck with diaphragms. On the other hand, the coefficient " $n$ " was assumed to be equal to $0,1,2$ or 3 depending on the assumed scenario. Overall the total bridge buoyancy was calculated using the above equation and five different assumptions, by considering:

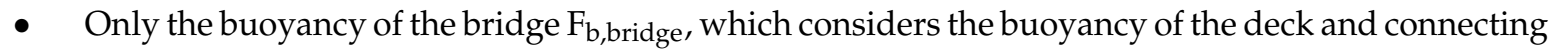
elements, assuming that all the trapped air has escaped from underneath the deck;

- The buoyancy of the bridge and the buoyancy of the trapped air, assuming that $50 \%\left(\mathrm{~F}_{\mathrm{b}, \text { brd+air50 }}\right)$ or $100 \%\left(\mathrm{~F}_{\mathrm{b}, \mathrm{brd}+\mathrm{air} 100}\right)$ of the volume of all three chambers is filled with air; and

- The buoyancy of the bridge and the buoyancy of the trapped air assuming that $50 \%\left(\mathrm{~F}_{\mathrm{b}, \mathrm{brd}+\mathrm{air} 50 \mathrm{ch}}\right)$ or $100 \%\left(\mathrm{~F}_{\mathrm{b}, \mathrm{brd}+\mathrm{air} 100 \mathrm{ch}}\right)$ of the volume of the actual number of flooded chambers is filled with air. This is expected to be a more accurate representation because the previous section revealed that, due to the complex temporal and spatial variation of the wave loading, the maximum uplift can 
occur anytime during the inundation process (any phase) (e.g., when one chamber is flooded or when several chambers are flooded).

While the buoyancy of the bridge itself is $4.67 \mathrm{kN}$, the buoyancy coming only from the trapped air is 5.40 or $10.79 \mathrm{kN}$, if $50 \%$ or $100 \%$, respectively, of the volume of all three chambers is filled with air.

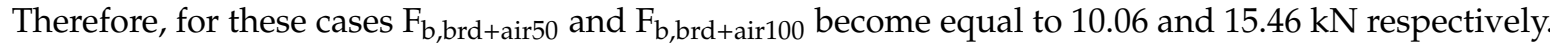
If only the actual flooded chambers are considered, then the buoyancy due to the trapped air is not constant for all wave heights, but varies between 1.80 and $10.79 \mathrm{kN}$, with the exact values shown in

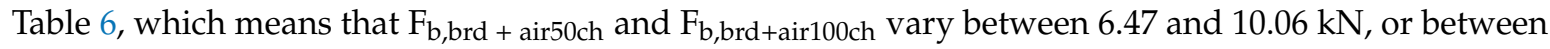
8.27 and $15.46 \mathrm{kN}$, respectively.

As shown in Figure 16, for the deck with cross-frames, all solitary waves (apart from the smallest one) and bores tested in this study introduced a hydrodynamic uplift that exceeded the buoyancy of the bridge $\left(\mathrm{F}_{\mathrm{b} \text {,bridge }}\right)$, by a factor of 3.01 on average and up to 6.38 maximum. For the deck with diaphragms, all solitary waves and bores tested in this study introduced a hydrodynamic uplift that exceeded the buoyancy of the bridge, by a factor of 3.91 on average and up to 6.72 maximum. When $50 \%$ of the volume of each chamber is assumed to be trapped with air, the magnitude of the buoyancy force is doubled; however, even in this case the measured uplift forces are larger than the buoyancy force for most waves, by a factor of 1.81 on average and up to 3.12 maximum. The largest buoyancy force is achieved when $100 \%$ of the volume of all chambers is assumed to be filled with air, in which case, the measured hydrodynamic uplift of the largest solitary waves, for both water depths and all the bores tested at $2.0 \mathrm{~m}$ water depth, still exceed the buoyancy force by a factor of 1.18 on average and up to 2.03 maximum. However, for the majority of the waves tested at $1.90 \mathrm{~m}$ water depth and some of the smallest solitary waves tested at $2.0 \mathrm{~m}$ water depth, the measured uplift forces are smaller than $F_{b, b r d+a i r 100}$. Therefore, although the mean value of the hydrodynamic uplift to the calculated buoyancy drops significantly and becomes equal to 1.18, this does not mean that the estimation of the buoyancy gives an accurate estimation of the wave-induced uplift for all wave heights, since the coefficient of variation CV (standard deviation to mean values) was $41 \%$.
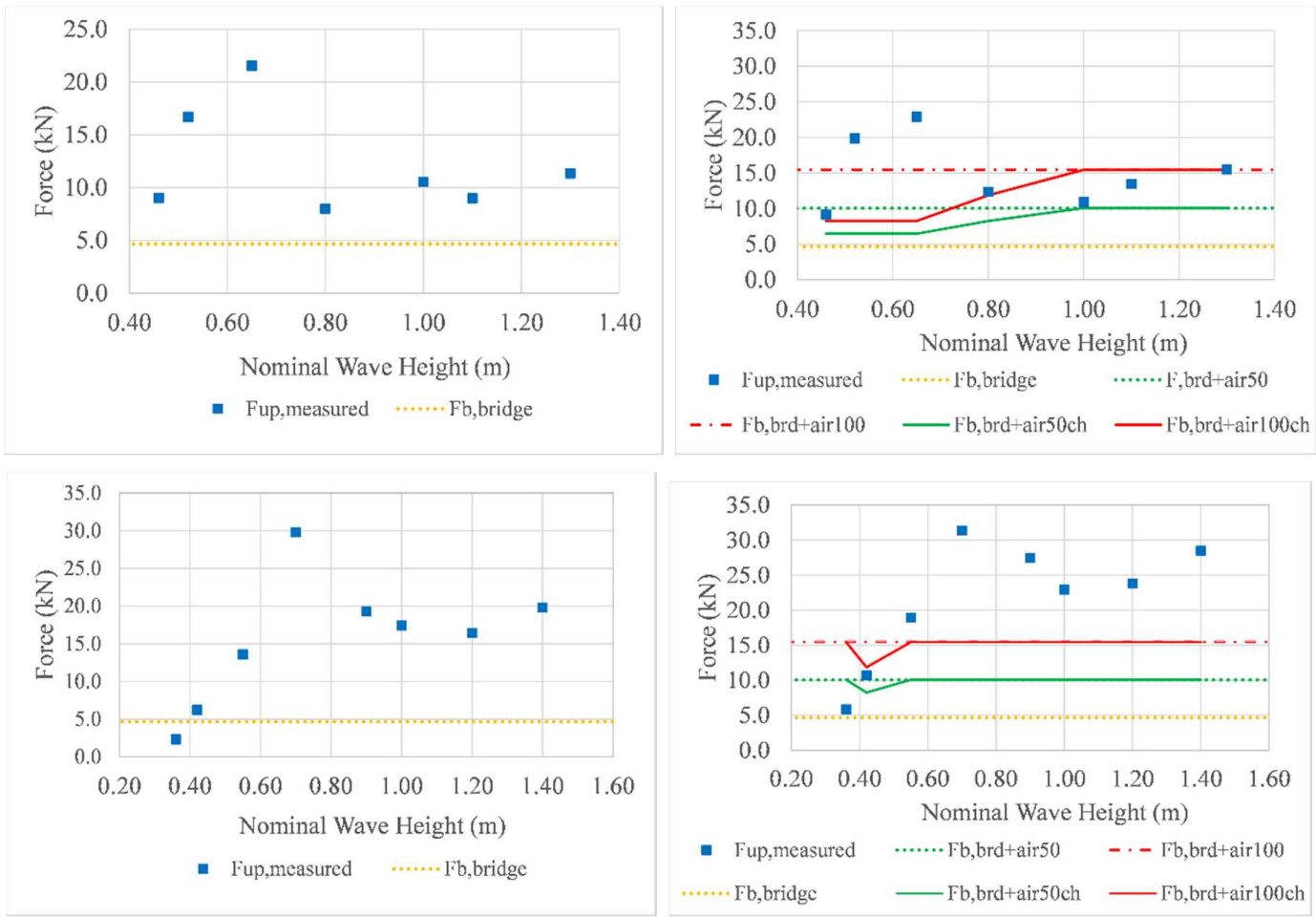

Figure 16. Calculated buoyancy and recorded maximum uplift forces for the deck with cross-frames (left) and the one with solid diaphragms (right), for $\mathrm{d}=1.90 \mathrm{~m}$ (top) and $\mathrm{d}=2.00 \mathrm{~m}$ (bottom). 
When the actual number of the flooded chambers is used in the calculation of the buoyancy, then as shown in Figure 16 (top-right) it gets closer to the measured hydrodynamic uplift for $\mathrm{d}=1.90 \mathrm{~m}$. However, the mean value of the hydrodynamic uplift to the calculated buoyancy and the CV are still high and equal to $2.04 \%$ and $41.6 \%$, respectively, for the $50 \%$ assumption $\left(\mathrm{F}_{\mathrm{b}, \mathrm{brd}+\mathrm{air} 50 \mathrm{ch}}\right)$, or $1.41 \%$ and $45.35 \%$, respectively, for the $100 \%$ assumption $\left(\mathrm{F}_{\mathrm{b}, \mathrm{brd}+\mathrm{air} 100 \mathrm{ch}}\right)$. This comparison verifies the inability of the buoyancy to predict the measured uplift and the importance of the hydrodynamic nature of the wave-induced loading that a bridge deck has to withstand.

\subsection{Increase of Uplift Forces vs. Buoyancy of Trapped Air}

In the previous section the comparison of the maximum total induced uplift (Fup) between the two deck types together with the maximum quasi-static component (Fup,qs), in terms of ratios (ST5/ST2) and subtraction (ST5-ST2), revealed a more consistent effect of the trapped air on Fup,qs than on Fup. If Table 4 is reviewed again, then it can be noticed that the coefficient of variation of the ratios (ST5/ST2) drops from 26\% for Fup to 23\% for Fup,qs; however, the respective values for the subtraction (ST5-ST2) drop from $61 \%$ to $33 \%$. This in turn indicates that the subtraction of Fup,qs between the two deck types does not vary as much as of Fup, and this could be probably attributed to the additional buoyancy generated by the trapped air and its more consistent effect on the quasistatic component of the wave-induced hydrodynamic uplift. To examine if this hypothesis is true, Table 6 shows a comparison of the subtraction of the maximum total uplift between the two deck types (Fup,ST5-Fup,ST2) as well as of the quasi-static uplift (Fup,qs,ST5-Fup,qs,ST2), with the calculated buoyancy generated by the trapped air $\left(\mathrm{F}_{\mathrm{b}, \mathrm{air}}=\mathrm{F}_{\mathrm{b}, 50}\right.$ or $\left.\mathrm{F}_{\mathrm{b}, 100}\right)$.

It must be clarified that, given the fact that two of the tested wave heights give significantly larger ratios than the rest, the table presents two different values for the mean, with "Mean" considering all the tested wave heights, and "Mean2" considering all the wave heights apart from the two outliers. The major findings emerging from Table 6 are the following:

- Assuming that $50 \%$ of the volume of the chambers is trapped with air gives a better estimation of the increase of both the total uplift and the quasi-static one witnessed by the deck with solid diaphragms, than the $100 \%$ hypothesis. This is true irrespective of whether all three chambers or the actual number of flooded chambers at the time of maximum uplift are considered in the calculation of the buoyancy. The mean value (without the outliers) of the ratios of the uplift increase (in ST5) to the buoyancy generated by the trapped air (Fup,sT5-Fup,sT2 $/ \mathrm{F}_{\mathrm{b}, \text { air }}$ ) is 1.61 and 3.22 for the $50 \%$ and $100 \%$ assumption, respectively.

- Using the actual numbers of the inundated chambers (at the instant that the maximum uplift occurs) in the calculation of the additional buoyancy gives closer results to the measured values than using all three chambers. Switching from the total to the actual number of chambers reduced the mean values from 1.61 to 1.26 and from 3.22 to 2.52 for the $50 \%$ and $100 \%$ hypotheses, respectively. For the quasi-static uplift, the respective reductions were from 1.63 to 1.37 and from 3.26 to 2.75 .

- The increase of the quasi-static force (Fup,qs) is better predicted than the increase of the total uplift by the buoyancy generated from the trapped air, with the mean values (that consider the outliers) being 1.75 and 3.49 for Fup,qs and 4.72 and 9.45 for Fup, for the 50\% and $100 \%$ assumption, respectively, and all the chambers inundated. If the two outliers are removed then the Fup and Fup,qs have very similar mean values, with the former showing even smaller mean values than the latter one. However, even in this case the correlation of the increase of Fup,qs with the buoyancy of the trapped air is better because than the one of Fup, because the coefficient of variation is $30.3 \%$ in the former case and $75.1 \%$ in the latter one. The reason behind this behavior is the fact that, as discussed in previous sections, although the buoyancy of the trapped air increases, consistently, the quasi-static component of the uplift force, this is not always reflected in the total uplift, because it is also affected by the slamming component, which is not affected by the air-entrapment in a consistent way (can either increase or decrease). 
These findings are adding to the body of knowledge regarding the role of air-entrapment. Moreover, they might prove useful for tsunami design of bridges, since they indicate that if the wave-induced uplift forces on a deck with cross-frames is known then the uplift of a deck with diaphragms could be estimated by considering the additional uplift coming from buoyancy of the trapped air.

Table 6. Comparison of the calculated buoyancy forces with the measured uplift forces on the deck with cross-frames (ST2) and the one with diaphragms (ST5).

\begin{tabular}{|c|c|c|c|c|c|c|c|c|c|c|c|}
\hline \multirow{3}{*}{ H (m) } & \multirow{3}{*}{$\underset{\text { ST5-ST2 }}{\text { Fup }}$} & \multirow{2}{*}{\multicolumn{2}{|c|}{$\begin{array}{l}\text { Buoyancy, Fb } \\
\text { Actual chamb. }\end{array}$}} & \multicolumn{4}{|c|}{ (Fup,ST5-Fup,ST2)/Fb } & \multicolumn{4}{|c|}{ (Fup,qs,ST5-Fup,qs,ST2)/Fb } \\
\hline & & & & \multicolumn{2}{|c|}{ All chamb. } & \multicolumn{2}{|c|}{ Actual chamb. } & \multicolumn{2}{|c|}{ All chamb. } & \multicolumn{2}{|c|}{ Actual chamb. } \\
\hline & & $\begin{array}{l}F_{b, 50} \\
(k N)\end{array}$ & $\begin{array}{c}\mathbf{F}_{\mathbf{b}, \mathbf{1 0 0}} \\
(\mathbf{k N})\end{array}$ & $\mathbf{F}_{\mathbf{b}, 50}$ & $F_{b, 100}$ & $\mathbf{F}_{\mathbf{b}, 50}$ & $F_{b, 100}$ & $F_{b, 50}$ & $\mathbf{F}_{\mathbf{b}, 100}$ & $\mathbf{F}_{\mathbf{b}, 50}$ & $F_{b, 100}$ \\
\hline 0.46 & 0.16 & 1.80 & 3.60 & 34.76 & 69.53 & 11.59 & 23.18 & 3.01 & 6.03 & 1.00 & 2.01 \\
\hline 0.52 & 3.18 & 1.80 & 3.60 & 1.70 & 3.39 & 0.57 & 1.13 & 1.78 & 3.56 & 0.59 & 1.19 \\
\hline 0.65 & 1.36 & 1.80 & 3.60 & 3.97 & 7.93 & 1.32 & 2.64 & 1.32 & 2.63 & 0.44 & 0.88 \\
\hline 0.80 & 4.38 & 3.60 & 7.19 & 1.23 & 2.46 & 0.82 & 1.64 & 2.35 & 4.70 & 1.57 & 3.13 \\
\hline 1.00 & 0.36 & 5.40 & 10.79 & 15.16 & 30.31 & 15.16 & 30.31 & 1.98 & 3.96 & 1.98 & 3.96 \\
\hline 1.10 & 4.48 & 5.40 & 10.79 & 1.20 & 2.41 & 1.20 & 2.41 & 2.20 & 4.39 & 2.20 & 4.39 \\
\hline 1.30 & 4.18 & 5.40 & 10.79 & 1.29 & 2.58 & 1.29 & 2.58 & 0.90 & 1.79 & 0.90 & 1.79 \\
\hline 0.36 & 3.50 & 5.40 & 10.79 & 1.54 & 3.08 & 1.54 & 3.08 & 2.34 & 4.68 & 2.34 & 4.68 \\
\hline 0.42 & 4.61 & 3.60 & 7.19 & 1.17 & 2.34 & 0.78 & 1.56 & 1.52 & 3.04 & 1.01 & 2.03 \\
\hline 0.55 & 5.48 & 5.40 & 10.79 & 0.98 & 1.97 & 0.98 & 1.97 & 1.50 & 3.00 & 1.50 & 3.00 \\
\hline 0.70 & 1.14 & 5.40 & 10.79 & 4.71 & 9.43 & 4.71 & 9.43 & 2.35 & 4.71 & 2.35 & 4.71 \\
\hline 0.90 & 8.19 & 5.40 & 10.79 & 0.66 & 1.32 & 0.66 & 1.32 & 1.30 & 2.59 & 1.30 & 2.59 \\
\hline 1.00 & 5.47 & 5.40 & 10.79 & 0.99 & 1.97 & 0.99 & 1.97 & 1.29 & 2.58 & 1.29 & 2.58 \\
\hline 1.20 & 6.25 & 5.40 & 10.79 & 0.86 & 1.73 & 0.86 & 1.73 & 1.13 & 2.26 & 1.13 & 2.26 \\
\hline \multirow[t]{5}{*}{1.40} & 8.61 & 5.40 & 10.79 & 0.63 & 1.25 & 0.63 & 1.25 & 1.25 & 2.49 & 1.25 & 2.49 \\
\hline & & & Mean & 4.72 & 9.45 & 2.87 & 5.75 & 1.75 & 3.49 & 1.39 & 2.78 \\
\hline & & & Mean2 & 1.61 & 3.22 & 1.26 & 2.52 & 1.63 & 3.26 & 1.37 & 2.75 \\
\hline & & & SD & 1.21 & 2.42 & 1.04 & 2.08 & 0.49 & 0.99 & 0.59 & 1.18 \\
\hline & & & $\mathrm{CV}(\%)$ & 75.1 & 75.1 & 82.5 & 82.5 & 30.3 & 30.3 & 43.1 & 43.1 \\
\hline
\end{tabular}

\section{Practical Recommendations for Engineering Design}

\subsection{Total Deck Uplift}

An important finding to emerge in this study is the existence of a complex interaction between the trapped air (underneath an elevated deck) with extreme waves, especially tsunami-like bores, which makes it challenging to accurately predict the effect of air on the wave-induced loading on an open-girder deck, and even more challenging on the individual structural components that support the deck. To decipher this complex interaction further research is necessary. In the meantime, in an attempt to provide a simple and practical approach for estimating the role of air, the previous section calculated and compared the buoyancy of the bridge with the maximum hydrodynamic uplift forces measured in the large-scale experiments. The results revealed that the buoyancy of the bridge cannot give a good estimate of the maximum hydrodynamic uplift applied, neither on decks with cross-frames nor on decks with solid diaphragms. On the other hand, interestingly the additional buoyancy generated by the air that is trapped between the solid diaphragms, can give a reasonable estimate of the increase of the uplift force between a deck with cross-frames and one with solid diaphragms. The above finding can be useful from a design point of view because it indicates that if the uplift force on a deck with cross-frames is known (e.g., from simplified predictive equations or single-phase incompressible computational fluid analyses (CFD)), then the maximum uplift on a deck with solid diaphragms can be estimated simply using Equation (6).

$$
\mathrm{F}_{\text {up,diaphr }}=\mathrm{F}_{\mathrm{up}, \text { cross }}+\mathrm{n} \gamma \alpha \mathrm{V}_{\mathrm{ch}}
$$


where $\mathrm{F}_{\mathrm{up} \text {,diaphr }}=$ total uplift force for a bridge with solid diaphragms and $\mathrm{F}_{\mathrm{up}, \mathrm{cross}}=$ total uplift force for a bridge with cross-frames. With this equation, an engineer can avoid the need to conduct more complex two-phase compressible CFD analyses of a deck with diaphragms, in order to understand the actual dynamic interaction of a bore with the trapped air and the wave-induced forces. This approach can be useful during the preliminary design phase where the engineer has to decide on the bridge type (e.g., composite bridge with steel girders and cross-frames or reinforced/pre-stressed concrete with diaphragms), because in reality although the decks with diaphragms are going to witness increased uplift forces due to the trapped air, they might be heavier and thus having a larger counter-acting weight. In such cases, the final decision regarding the bridge type will be made based on optimization of performance and cost, as it is usually the case with the design of such structures against other natural hazards (e.g., earthquakes).

The previous section also demonstrated that, due to the complex temporal and spatial evolution of the wave loading during the bridge inundation, the maximum hydrodynamic uplift can occur at different time instants for different wave heights, where a different number of chambers has been flooded. Using the actual number of flooded chambers for the calculation of the buoyancy of the trapped air, the estimation of the increase of the hydrodynamic uplift becomes more accurate. However, since this information is not available unless CFD analyses or hydrodynamic experiments have been conducted, for design purposes it can be assumed that all the chambers of a deck are flooded and that $50 \%$ of their volume is filled with air. This percentage is recommended because it gave the best overall prediction in terms of a mean value for all the waves tested in this study; however, it must be clarified that it did not give a conservative value for all wave heights. In fact, for some of the largest bores, it under-predicted the uplift. For a conservative estimate, engineers could assume $100 \%$ of the volume of the chambers to be filled with air; however, this case can lead to significant over-prediction of the effect of air. Therefore, a percentage between $50 \%$ and $100 \%$ might be the optimum solution, which will be both conservative and as economical as possible.

\subsection{Non-Dimensional Uplift Curves for Bearings and Connections}

The majority of the studies conducted to date have focused on the total forces that extreme waves apply on structures, and several studies have developed simplified predictive equations for both the maximum horizontal (Fh) and uplift (Fup) forces. However, as discussed previously, more recent research (e.g., $[15,28]$ ) has emphasized the need to examine the effects on individual structural components and connections, and provide guidance on the maximum forces for which these components have to be designed in order to be able to withstand extreme events such as tsunamis. To this end, it was deemed beneficial to calculate the non-dimensional ratios of the maximum uplift force measured in each bearing set (Fup,brngs,Gi) and column set (Fup,col.i) to the maximum total deck uplift (Ftot,up), and the results for the deck with cross-frames are presented in Figure 17 for all the tested solitary waves and bores. It must be clarified that each set of bearings (or columns) consists of two separate bearings (or columns), corresponding to the two bent caps that support the superstructure. The figure verifies that the bearings of the offshore girders (G1 and G2) attract the largest percentage of the total uplift consistently irrespective of the wave height, with the latter one reaching about $57 \%$ of Fup for solitary waves and $60 \%$ for bores. This is an alarming finding because it demonstrates that the common assumption of distributing the tsunami uplift force to all the bearings-in which case each bearing set would get about $25 \%$ of the deck uplift-is not accurate. This trend is also true for the columns, with the offshore columns attracting the largest percentage of the total uplift, which reached $79 \%$ of Ftot,up for solitary waves and $90 \%$ for bores in the hydrodynamic experiments.

It is worth noting that the largest uplift in the offshore structural components was also observed in the case of steel bearings (shown in [28]); however, in that case the largest percentage of the deck uplift was taken by the bearings of the first offshore girder, while in the case of elastomeric bearings (presented herein) this uplift seems to be taken by the bearings of the two girders located offshore of the C.G. In fact, in the former case, the offshore bearings (G1) and column (col.1) have to withstand up 
to $97 \%$ and $124 \%$ of the total deck uplift, respectively, which is significantly higher than the $60 \%$ and $90 \%$ ratios characterizing the deck with elastomeric bearings. This could be attributed to the fact that (a) the two types of bearings (steel and elastomeric) have totally different stiffness, which affects the distribution of the applied loading; and (b) the elastomeric bearings allow the deck to rotate, altering the applied wave pressures, loading, and the wave-structure interaction. Further investigation is required in order to quantify the significance of each of the two effects.
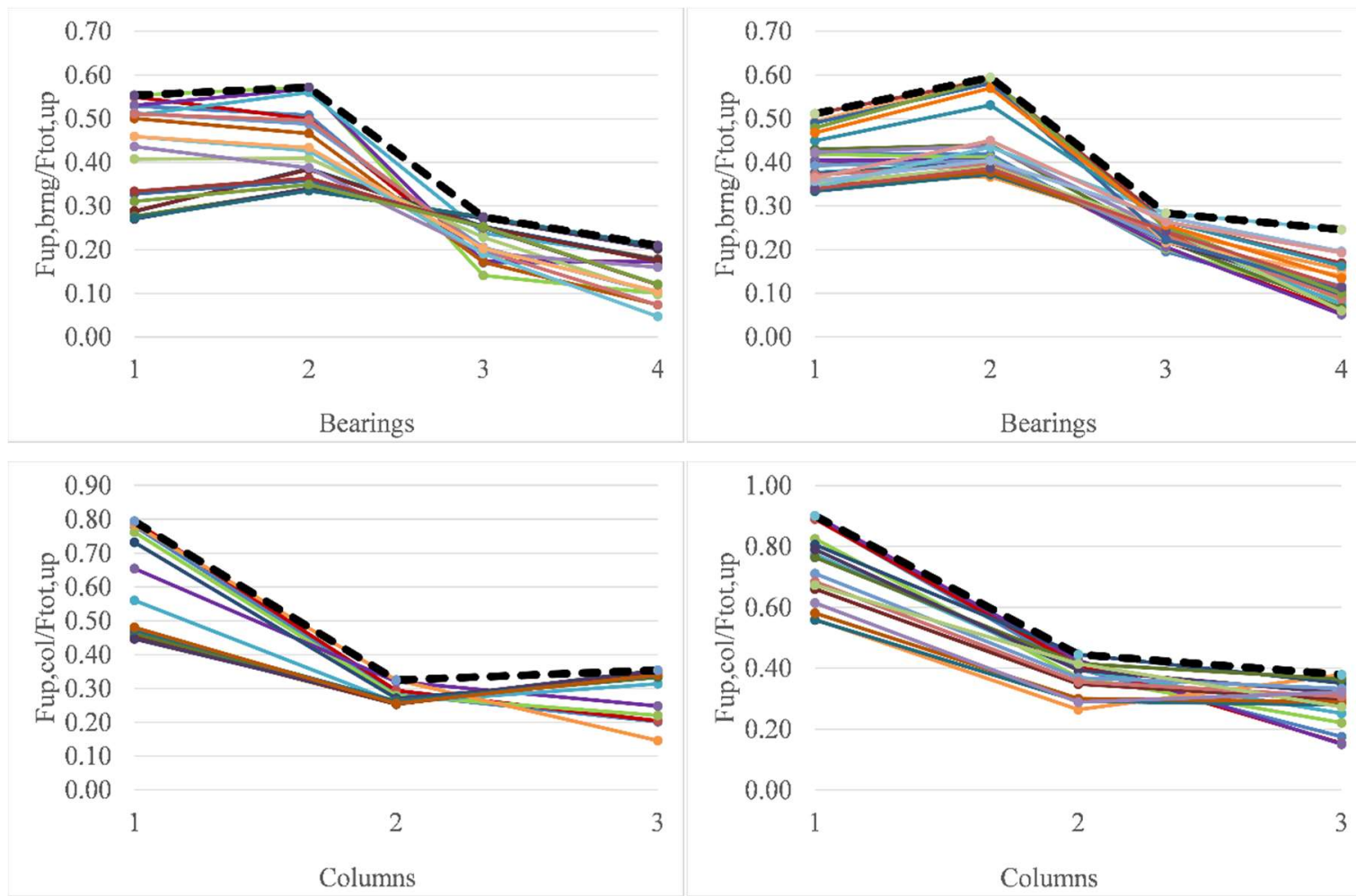

Figure 17. Maximum normalized uplift forces in bearings (top) and columns (bottom) of the deck with cross-frames, for all the solitary waves (left) and bores (right) tested in the flume.

Figure 18 shows the envelopes of the ratios (Fup,brngs,Gi/Ftot,up) and (Fup,col.i/Ftot,up) for both deck types. Interestingly, despite the significant differences between the wave-structure interaction and forces introduced by solitary waves and bores, the envelopes of the two wave types are very similar for the deck with cross-frames (ST2), with the bores tending to yield larger values than the solitary waves. This indicates that, from a design point of view, the bearings, columns, and connections could be designed for a certain level of uplift even if the exact wave type is not known. For the deck with solid diaphragms, the differences between the non-dimensional envelopes of the two wave types are more significant, and show opposite trends than the deck with cross-frames, with the bores introducing smaller percentages of the uplift forces in the offshore components than the solitary waves. The larger differences between the two wave types in the deck with solid diaphragms could be attributed to complex effect of the trapped air, which, as seen in previous sections, is different for solitary waves and bores. Surprisingly, although the trapped air in ST5 was seen to increase the total deck uplift (Ftot,up), it decreased the percentage of the uplift forces in the offshore bearings, which reached about $50 \%$ for the deck with solid diaphragms and $60 \%$ for the one with cross-frames.

To translate the above findings into practical information for engineers, Figure 19 presents normalized uplift forces for all the bearings and both deck types, which could potentially be used for design purposes. For each deck type, two different curves have been developed. In design alternative 1, all the bearing sets upstream of the center of the gravity (G1 and G2) are designed for the same high level of uplift, which is $60 \%$ for deck ST2 and 50\% for ST5, while the bearings downstream 
of the C.G. are designed for a smaller percentage, which is $28 \%$ and $26 \%$ for the two deck types, respectively. In design alternative 2, all bearings are designed for the same level of uplift ( $60 \%$ for ST2 and $50 \%$ for ST5, for each set of bearings). Although the first alternative results in a reduced bearing cost since half of the bearings will have a smaller size, the second approach is more conservative and easier from a construction point of view, because all bearings will be identical. It is up to the engineer to decide the best approach; however, it must be clarified that (a) the above percentages and non-dimensional design curves were developed using the measured experimental data, which means that for design purposes they should be scaled using a safety factor to account for the unknowns; and (b) the limitations described in the next section can affect the presented values, which might have to be modified depending on the bridge location and design conditions.

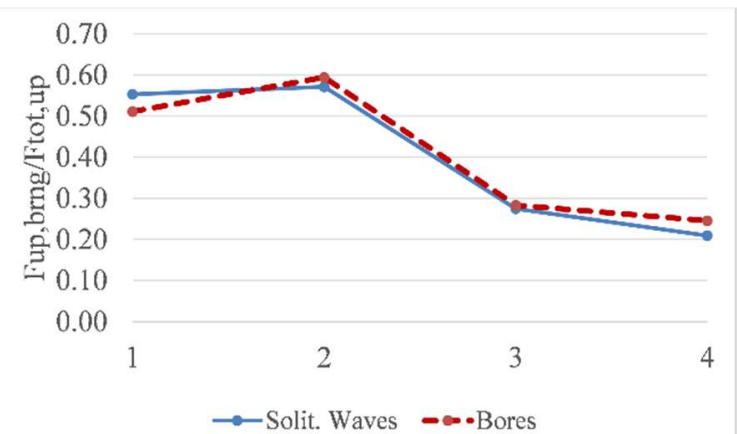

Bearings

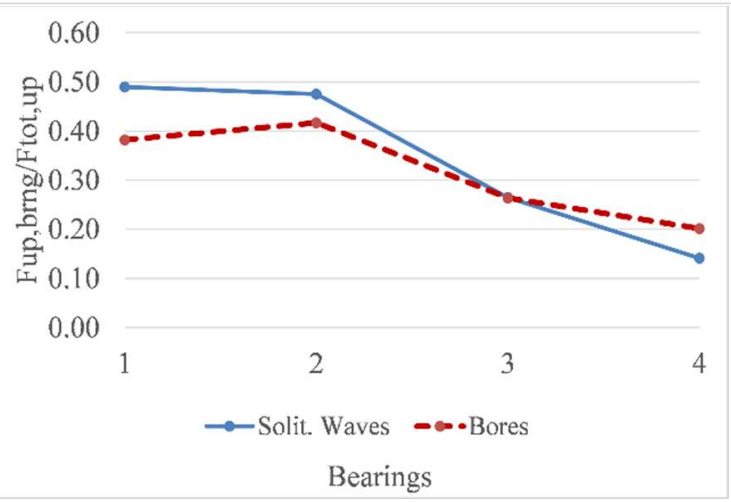

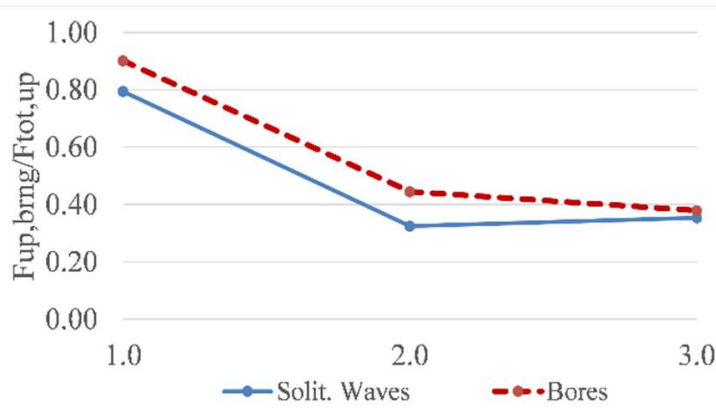

Columns

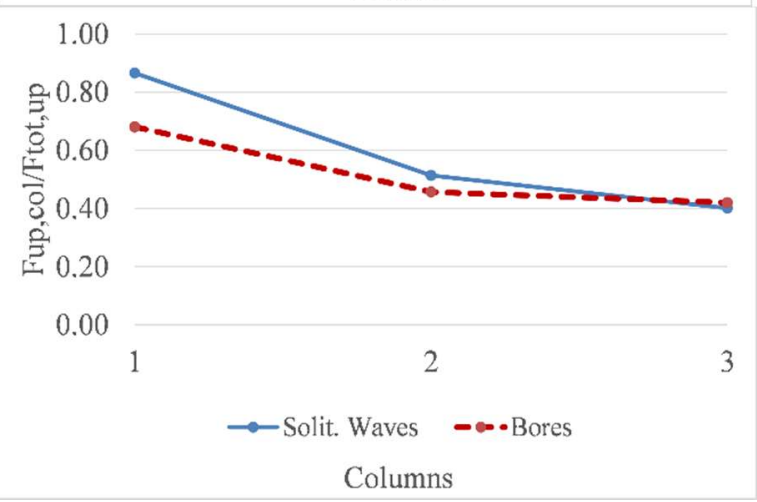

Figure 18. Envelopes of maximum normalized uplift forces in bearings (left) and columns (right) of the deck with cross-frames (top) and the one with solid diaphragms (right).

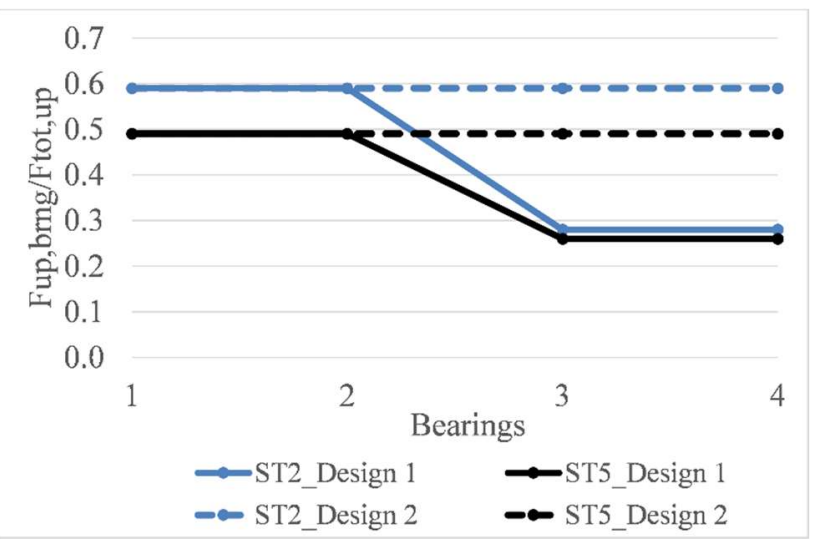

Figure 19. Non-dimensional design curves for the elastomeric bearings and connections of open-girder decks with cross-frames (ST2) and solid diaphragms (ST5). 


\subsection{Limitations and Future Work}

The current study has advanced the understanding of the role of air trapped beneath open girder decks and has provided practical information for engineers. However, this information and the above non-dimensional design curves are limited to:

- $\quad$ Elastomeric bearings. For other type of bearings (e.g., steel bearings) the readers can use the information provided in [28].

- Bridges with four or more girders. Although in the experiments the deck had four girders, the non-dimensional curves can be used for a larger number of girders, since in this case the actual ratios are expected to be smaller.

- Decks with similar dimensions and dimension ratios (girder height to deck width, overhang width to deck width) as the one tested in the experiments, and without rails. For example, if a deck has a larger girder height or the same height but solid rails, then the moment arm of the horizontal force (Fh) will increase, which would consequently increase the overturning moment resulting in increased uplift in the offshore bearings and other structural components.

- The curves of the design alternative 1 presented in Figure 19, which show reduced design values for all the bearings on the onshore side of the deck C.G. have been developed for the scenario in which the tsunami flows only in one direction. In reality though, the tsunami will flow in two directions, one direction when it initially impacts and inundates the coast, and the opposite direction when the tsunami retracts back to the ocean. This means that during the reverse flow the onshore bearings will witness larger uplift forces than the offshore ones, but it is unclear if they will be larger than the $28 \%$ of the Ftot,up applied during the first impact of the bore on the offshore side of the deck. Therefore, future research should examine the effects of the reverse flow, especially given the fact that, in such a case, significant debris can accumulate on the onshore side of the deck.

The findings and conclusions presented in this paper were reached based on (1:5) scaled experiments of tsunami impact on bridge decks-the largest scale conducted to date-however, the results might still be subjected to scale effects, which means that additional modifications might be required in order make the results applicable to full-scale bridges. Moreover, the non-dimensional design curves are applicable only to bearings and no other structural components below the bearings, such as columns and foundations. For such components the uplift demand is expected to be governed by the overturning moment generated mainly by the horizontal tsunami load, which could yield uplift forces in the members (e.g., at the bottom of the offshore column or in the offshore piles), with magnitudes several times higher than the total deck uplift. Therefore, for the design of these bridge members, engineers are advised to conduct structural analyses using load cases similar to the ones described in [28]. Last but not least, in the concept of tsunami design guidelines, the non-dimensional curves will have to be scaled up in order to account for possible unknowns and uncertainties generated by different sources, such as the fact that they were developed based on (i) a limited number of wave heights, (ii) results from scaled experiments, and (iii) without consideration of the effect of debris and reverse flow.

\section{Summary and Conclusions}

In response to the extensive damage to coastal bridges observed in recent tsunamis, this study attempts to enhance the understanding of tsunami-induced effects on two common bridge types, an open-girder deck with cross-frames and one with solid diaphragms. The main difference between the two deck types is that the latter type traps air in the chambers between the deck and the solid diaphragms. Although previous studies have examined the role of trapped air, the current investigation advances the understanding of this role due to (a) the large scale (1:5) of the hydrodynamic experiments, which enabled the physical modeling of a realistic bridge deck to be undertaken with structural components used in current practice, such as a reinforced concrete deck, steel girders, cross-frames, 
shear-keys, and elastomeric bearings; and (b) the extent of the testing program, which included not only unbroken solitary waves that were used in the majority of previous studies focusing on the role of air-entrapment in elevated decks, but also more realistic tsunami-like transient bores. Other features that add to the novelty of the current study is the use of flexible connections (elastomeric bearings) between the superstructure and substructure, which allowed the deck to translate and rotate, simulating; thus, the wave-structure interaction during the tsunami inundation, and the measurement of not only the total wave forces but the demand in individual bearings, columns, shear keys, and bent cap.

From the research that has been undertaken, it is concluded that irrespective of the deck type, the maximum horizontal force for all bores and some solitary waves, occurs at the time the wave impacts the offshore face of the bridge. This is not necessarily true for the uplift force, which can be maximized at different instants of the bridge inundation process. Moreover, all waves generate significant overturning moment, which has a governing effect on the uplift demand in the elastomeric bearings located offshore of the center of gravity (C.G.) of the deck. In terms of the structural response and resistance mechanism, both deck types are characterized by four different phases, among which: (a) a short-duration phase (ph. 1) corresponding to the time of the first wave impact on the offshore side of the deck, at which point the slamming horizontal and vertical forces together with the moment are maximized, introducing significant upward movement of the deck and a governing rotational structural mode, which maximizes, consequently, the clockwise rotation and the uplift forces in the offshore bearings and columns; and (b) a longer-duration phase (ph. 2) that follows the previous phase and lasts until the flooding of the center chamber is complete, during which the deck witnesses significant uplift forces but small moment and rotation due to the fact that the wave is approaching the point of rotation, and the structural response is governed by a translational mode in the vertical direction that tends to introduce the maximum uplift demand in the structural members close to the center of gravity of the deck.

Despite the similarities observed in the behavior of the two deck types, the air-entrapment associated with the solid diaphragms has a major effect on the tsunami loading, wave-structure interaction, and structural response of the bridge. In particular, the trapped air:

- Modifies significantly the wave flow in the chambers and introduces a different pattern of pressures on the girders and below the deck. However, the exact effect depends on the wave type. In the case of solitary waves, the pressure histories consistently (i) reach their maximum values before the wave reaches the girder and the deck, due to the fact that the wave pressure is transferred to the bridge through the compressed air; and (ii) have two characteristic peaks, smoother and with a longer duration than the case without trapped air, due to the nonlinear wave-air interaction and the cushioning effect. However, these effects are not always observed in the case of bores, revealing the existence of a more complex dynamic interaction between the air and the tsunami-like bores than in the case of simplified solitary waves.

- Can increase the pressures below the deck by up to a factor of 16.8; however, this effect is not consistent for all wave heights and in all chambers or girders. Some chambers witness reduced pressures due to the presence of air, which means that these pressures are not purely hydrostatic ones, but there is a significant hydrodynamic component undergoing a complex interaction with the trapped air. Moreover, the different effect on the pressures in consecutive chambers and on the girders indicates that the wave is being affected by the interaction with the air in the first chamber, resulting in the modification of the flow and the induced pressures in the rest of the chambers.

- Has a small or negligible effect on the maximum horizontal forces for most waves, since the maximum value tends to occur at the initial impact of the waves on the offshore girder (true for all bores and several solitary waves). However, after the initial peak, the horizontal forces have different patterns, with the deck with diaphragms witnessing smoother peaks than the deck with cross-frames due to the existence of the compressible air. 
- Affects the uplift forces more than the horizontal ones, by increasing the duration and magnitude of most uplift peaks observed in the time-histories. The exact increase in the uplift forces depends on the wave height and wave type, and in the current experimental work the average increase of the total uplift force was $39 \%$ and the maximum increase was $148 \%$.

Introduces a different effect on the uplift forces when the deck is impacted by solitary waves instead of bores. For bores the air tends to alter mainly the pattern and magnitudes of the uplift forces in phases 2 and 3, which occur when the wave is flooding the chambers, while it has a negligible effect on the first uplift peak that occurs when the wave hits the offshore overhang. However, for solitary waves the trapped air modifies the entire vertical force histories and the phase themselves, so that after the occurrence of the first uplift peak, the vertical force does not immediately drop to zero but keeps increasing both in magnitude and duration. This different behavior emanates from the fact that the tip of a solitary wave starts compressing the trapped air in the first chamber, while the crest of the wave is still at the location of the offshore overhang, which means that uplift pressures are applied in chamber 1 before the pressures below the overhang are minimized.

Apart from the significant effect of the trapped air on the pressures and total forces, the data presented herein revealed that the air also tends to increase the maximum overturning moment (maxOTM) for most waves, by $32 \%$ on average, which has not been discussed in previous studies. For some bore heights the effect on maxOTM is negligible. However, even in this case, the moment histories are significantly modified, indicating a different form of wave-structure interaction. To investigate the role of air further, the total forces were separated into a slamming and quasi-static component using the empirical mode decomposition method, and the results revealed that the trapped air (a) had a noticeable effect on the temporal variation of the slamming forces by tending to smooth out the impulsive peaks in the force histories; however, it has a complex and inconsistent effect on the maximum slamming uplift force (especially the one caused by bores), which could either increase or decrease depending on the wave type and wave height; and (b) has a consistent effect on the quasi-static component of the uplift force by increasing its magnitude for both wave types by at least $30 \%$ for most waves and up to $142 \%$, with the largest increase occurring for the smallest wave height. However, this increase is not always translated into an equal increase of the maximum total uplift force, because the latter can occur at a different instant in time than the maximum quasi-static component. It is also affected by the slamming component, which could be increased or decreased by the trapped air.

One of the main objectives of this study was to draw attention to the bearings and connections, which were seen to be the most vulnerable components in recent tsunamis. Interestingly, although the air-entrapment tends to increase the total uplift force, it does not have a similar effect on the uplift forces in individual bearings and columns. In fact, the uplift in the bearings and columns offshore of the C.G. of the deck might stay the same or even decrease due to the presence of the air, even though the total deck uplift increases for the same waves. This can be attributed to the fact that the uplift in these components is significantly affected by the clockwise overturning moment or a combination of moment and uplift forces. On the other hand, the trapped air increases consistently the forces in the onshore columns by a mean value of $105 \%$, while the respective increase in the onshore bearings is $53 \%$ and is not always consistent. Deciphering the effect of the air on the forces of the bearings is more challenging than the effect on the columns due to the frictional contact between the shear keys and the girders. The existence of the trapped air results in a different wave-structure interaction for the two bridge specimens altering the structural response (vertical translations and rotations) and the forces that each bridge component has to withstand. Overall though, the air reduces the ratio of the maximum uplift force in the offshore bearings to the respective one in the onshore bearings, from 5.17 (mean value) in the case of cross-frames to 3.98 in the case of solid diaphragms.

Comparison of the maximum measured uplift in the deck with solid diaphragms and the calculated buoyancy revealed that even if $100 \%$ of all three chambers were assumed to be trapped with air the generated buoyancy force cannot reach the total uplift forces caused by the largest waves, verifying the importance of the hydrodynamic component of these forces. On the other hand, the additional 
buoyancy generated only by the trapped air in the chambers can give a reasonable estimate of the increase of the uplift force between a deck with cross-frames and one with solid diaphragms. In fact, assuming that $50 \%$ of the volume of the chambers is trapped with air gives a better estimation of the increase of both the total uplift and the quasi-static one witnessed by the deck with solid diaphragms, than the $100 \%$ hypothesis, which gives conservative results. The above finding can be useful from a design point of view because it indicates that if the uplift force on a deck with cross-frames is known, then the maximum uplift on a deck with solid diaphragms can be estimated via the simple calculation of the additional buoyancy, avoiding the need to conduct more complex two-phase CFD analyses.

The last section of this study presented some practical recommendations for the engineering design of bridges against tsunamis, including non-dimensional uplift curves for elastomeric bearings of the two aforementioned bridge types. Despite the significant differences between the wave-structure interaction and forces introduced by solitary waves and bores, an important finding emerging from this study is that the envelopes and non-dimensional curves of the two wave types are relatively similar, which can be useful for design purposes. For the deck with cross-frames, the bearings of each girder located offshore of the center of gravity of the deck (C.G.) should be able to withstand at least $60 \%$ of the total deck uplift, while for the deck with solid diaphragms the respective value is $50 \%$. Both of these numbers are significantly higher than $25 \%$ which is, approximately, the percentage given by the assumption of equal distribution of the uplift force to all bearings. Engineers could either design the bearings onshore to the C.G. for smaller uplift forces than the offshore ones, or make all the bearings the same size in order to facilitate the construction process. However, before they make a decision they should understand the limitations of this work and be able to select appropriate load factors in order to account for the associated uncertainties.

In conclusion, the present study reveals the insufficiency of the current approach of quantifying (1) the tsunami-induced effects on bridges only in terms of the maximum horizontal and vertical force; and (2) the effect of trapped air only on these forces. In order to advance the state of the art in the field, it is necessary to examine the overturning moment, the interaction of this moment with the deck uplift, the temporal variation of the induced effects, the wave-structure interaction, the structural response, and the uplift demand in individual bearings and columns, and understand how all these parameters are affected by the air trapped beneath the deck. Last but not least, the significant differences witnessed in the wave effects introduced by solitary waves, which are commonly used for the study of tsunami loading on structures, and more realistic bores, highlight the need to direct future research efforts towards further investigation of the physics underlying the wave impact of the two wave types. The study presented herein focused on bridge decks; however, the findings could contribute to the understanding of tsunami-induced forces on other elevated deck-type structures, such as wharves and offshore platforms.

Author Contributions: I.B. and D.I. conceived the need to examine the effect of air-entrapment on the tsunami-induced forces in bridge superstructures, including the demand on connections and components, and designed and executed the large-scale experiments described in this paper. D.I. conducted the in-depth analyses of the experimental data, developed the technical content presented in this paper, and wrote the first draft, while I.B. provided advice, feedback, and editing of the paper.

Funding: The hydrodynamic experiments and a portion of the analyses presented in this paper were funded by the Federal Highway Administration (FHWA) under Contract No. DTFH61-07-C-00031, "Improving the Seismic Resilience of the Federal-Aid Highway System", awarded to Ian Buckle, PI. The majority of the comprehensive analyses of the experimental data presented herein, the development of practical recommendations for engineering design, and the preparation of this manuscript was funded by the Oregon Department of Transportation (ODOT) under Contract No. 32399, "Verification of Tsunami Bridge Design Equations" awarded to Ian Buckle, PI, and Denis Istrati, Co-PI.

Acknowledgments: During the FHWA-funded project, technical guidance was provided by the following FHWA Representatives of the Contracting Officer (COR): Wen-huei (Phillip) Yen, Fred Faridazar, and Sheila Duwadi. During the ODOT-funded project, research coordination was provided by Jon Lazarus and technical guidance was given by Bruce Johnson and Albert Nako from ODOT. Any findings and opinions contained in this paper are those of the authors and do not necessarily reflect those of the funding agencies. The authors also wish to recognize Pedro Lomonaco and Solomon Yim, who assisted with the design and conduct of the experiments. Moreover, 
the authors acknowledge Tao Xiang, Anastasia Bitsani, Patrick Laplace, Chad Lyttle, Todd Lyttle, Tim Maddux, Alicia Lyman-Holt, James Batti, and Jeff Gent for their technical assistance during the experiments. In addition, the authors wish to thank Daniel Cox and Chris Higgins for agreeing to the authors' modification and upgrade of their experimental setup so it could be used for the tsunami experiments described in this paper. Last but not least, the authors appreciate the assistance provided by Information Technology at UNR and access to the HPC resources necessary to run the advanced CFD and FSI numerical analyses for the hydrodynamic design of the experiments.

Conflicts of Interest: The authors declare no conflicts of interest.

\section{References}

1. Unjoh, S. Bridge damage caused by tsunami. Jpn. Assoc. Earthq. Eng. 2007, 6, 6-28.

2. Maruyama, K.; Tanaka, Y.; Kosa, K.; Hosoda, A.; Arikawa, T.; Mizutani, N.; Nakamura, T. Evaluation of tsunami force acting on bridge girders. In Proceedings of the Thirteenth East Asia-Pacific Conference on Structural Engineering and Construction (EASEC-13), Sapporo, Japan, 11-13 September 2013.

3. Kosa, K. Damage analysis of bridges affected by tsunami due to Great East Japan Earthquake. In Proceedings of the Symposium on Engineering Lessons Learned from the 2011 Great East Japan Earthquake, Tokyo, Japan, 1-4 March 2012.

4. Kawashima, K. Damage of bridges due to the 2011 Great East Japan Earthquake. In Proceedings of the International Symposium on Engineering Lessons Learned from the 2011 Great East Japan Earthquake, Tokyo, Japan, 1-4 March 2012.

5. Kasano, H.; Oka, J.; Sakurai, J.; Kodama, N.; Yoda, T. Investigative research on bridges subjected to tsunami disaster in 2011 off the pacific coast of Tohoku earthquake. In Australasian Structural Engineering Conference 2012: The Past, Present and Future of Structural Engineering; Engineers Australia: Barton, Australia, 2012; p. 51.

6. Hayashi, H. Study on tsunami wave force acting on a bridge superstructure. In Proceedings of the 29 th US-Japan Bridge Engineering Workshop, Tsukuba, Japan, 11-13 November 2013.

7. Lau, T.L.; Ohmachi, T.; Inoue, S.; Lukkunaprasit, P. Experimental and numerical modeling of tsunami force on bridge decks. In Tsunami-A Growing Disaster; InTech: London, UK, 2011. [CrossRef]

8. Seiffert, B.; Hayatdavoodi, M.; Ertekin, R.C. Experiments and computations of solitary-wave forces on a coastal-bridge deck. Part I: Flat plate. Coast. Eng. 2014, 88, 194-209. [CrossRef]

9. Mazinani, I.; Ismail, Z.; Hashim, A.M.; Saba, A. Experimental investigation on tsunami acting on bridges. Int. J. Civ. Archit. Struct. Constr. Eng. 2014, 8, 1040-1043.

10. Rahman, S.; Akib, S.; Shirazi, S.M. Experimental investigation on the stability of bride girder against tsunami forces. Sci. China Technol. Sci. 2014, 57, 2028-2036. [CrossRef]

11. Bricker, J.D.; Nakayama, A. Contribution of trapped air, deck superelevation, and nearby structures to bridge deck failure during a tsunami. J. Hydraul. Eng. 2014, 140, 05014002. [CrossRef]

12. Kataoka, S.; Kaneko, M. Estimation of Wave Force Acting on Bridge Superstructures due to the 2011 Tohoku Tsunami. J. Disaster Res. 2013, 8, 605-611. [CrossRef]

13. Nakao, H.; Zhang, G.; Sumimura, T.; Hoshikuma, J. Numerical assessment of tsunami-induced effect on bridge behavior. In Proceedings of the 29th US-Japan Bridge Engineering Workshop, Tsukuba, Japan, 11-13 November 2013; pp. 11-13.

14. Azadbakht, M.; Yim, S.C. Simulation and estimation of tsunami loads on bridge superstructures. J. Waterw. Port Coast. Ocean Eng. 2014, 141, 04014031. [CrossRef]

15. Istrati, D.; Buckle, I.G. Effect of fluid-structure interaction on connection forces in bridges due to tsunami loads. In Proc 30th US-Japan Bridge Engineering Workshop; Department of Transportation's Federal Highway Administration: Washington, DC, USA, 2014.

16. Wei, Z.; Dalrymple, R.A. Numerical study on mitigating tsunami force on bridges by an SPH model. J. Ocean Eng. Mar. Energy 2016, 2, 365-380. [CrossRef]

17. Hoshikuma, J.; Zhang, G.; Nakao, H.; Sumimura, T. Tsunami-induced effects on girder bridges. In Proceedings of the International Symposium for Bridge Earthquake Engineering in Honor of Retirement of Professor Kazuhiko Kawashima, Tokyo, Japan, 15 March 2013.

18. McPherson, R.L. Hurricane Induced Wave and Surge Forces on Bridge Decks. Ph.D. Thesis, Texas A\&M University, College Station, TX, USA, 2008.

19. Hayatdavoodi, M.; Seiffert, B.; Ertekin, R.C. Experiments and computations of solitary-wave forces on a coastal-bridge deck. Part II: Deck with girders. Coast. Eng. 2014, 88, 210-228. [CrossRef] 
20. Cuomo, G.; Shimosako, K.I.; Takahashi, S. Wave-in-deck loads on coastal bridges and the role of air. Coast. Eng. 2014, 56, 793-809. [CrossRef]

21. Seiffert, B.R.; Cengiz Ertekin, R.; Robertson, I.N. Effect of entrapped air on solitary wave forces on a coastal bridge deck with girders. J. Bridg. Eng. 2015, 21, 04015036. [CrossRef]

22. Bozorgnia, M.; Lee, J.J.; Raichlen, F. Wave structure interaction: Role of entrapped air on wave impact and uplift forces. Coast. Eng. Proc. 2011, 1, 57. [CrossRef]

23. Xu, G.; Cai, C.S.; Chen, Q. Countermeasure of Air Venting Holes in the Bridge Deck-Wave Interaction under Solitary Waves. J. Perform. Constr. Facil. 2016, 31, 04016071. [CrossRef]

24. Qu, K.; Tang, H.S.; Agrawal, A.; Cai, Y. Hydrodynamic effects of solitary waves impinging on a bridge deck with air vents. J. Bridg. Eng. 2017, 22, 04017024. [CrossRef]

25. Madsen, A.; Fuhrman, D.R.; Schäffer, H.A. On the solitary wave paradigm for tsunamis. J. Geophys. Res. 2008, 113, 286-292. [CrossRef]

26. Chan, I.C.; Liu, L.F. On the run-up of long waves on a plane beach. J. Geophys. Res. 2012, 117, 72-82. [CrossRef]

27. Leschka, S.; Oumeraci, H. Solitary waves and bores passing three cylinders-effect of distance and arrangement. Coast. Eng. Proc. 2014, 1, 39. [CrossRef]

28. Istrati, D.; Buckle, I.; Lomonaco, P.; Yim, S. Deciphering the Tsunami Wave Impact and Associated Connection Forces in Open-Girder Coastal Bridges. J. Mar. Sci. Eng. 2018, 6, 148. [CrossRef]

29. Bradner, C.; Schumacher, T.; Cox, D.; Higgins, C. Experimental setup for a large-scale bridge superstructure model subjected to waves. J. Waterw. Port Coast. Ocean Eng. 2010, 137, 3-11. [CrossRef]

30. Istrati, D.; Buckle, I.; Lomonaco, P.; Yim, S.; Itani, A. Large-scale experiments of tsunami impact forces on bridges: The role of fluid-structure interaction and air-venting. In Proceedings of the 26th International Ocean and Polar Engineering Conference, Rhodes, Greece, 26 June-2 July 2016.

31. AASHTO LRFD Bridge Design Specifications; American Association of State Highway and Transportation Officials: Washington, DC, USA, 2012.

32. Ghosh, S.; Reins, G.; Koo, B.; Wang, Z.; Yang, J.; Stern, F. Plunging wave breaking: EFD and CFD. In International Conference on Violent Flows; National University: Fukuoka, Japan, 2007.

33. Istrati, D. Large-Scale Experiments of Tsunami Inundation of Bridges including Fluid-Structure-Interactio. Ph.D. Thesis, University of Nevada, Reno, Nevada, 2017.

34. Peregrine, D.H.; Bredmose, H.; Bullock, G.B.; Obhrai, C.; Wolters, G.; Muller, G. Violent water wave impact on walls and the role of air. In Proceedings of the 29th International Conference on Coastal Engineering, Lisbon, Portugal, 19-24 September 2004; pp. 4005-4017.

35. Robertson, I.N.; Riggs, H.R.; Mohamed, A. Experimental results of tsunami bore forces on structures. In Proceedings of the ASME 2008 27th International Conference on Offshore Mechanics and Arctic Engineering, Estoril, Portugal, 15-20 June 2018; American Society of Mechanical Engineers: New York, NY, USA, 2008; pp. 509-517.

36. Jose, J.; Podrazka, O.; Obhrai, C.; Gudmestad, O.T.; Cieslikiewicz, W. Methods for Analysing Wave Slamming Loads on Truss Structures Used in Offshore Wind Applications Based on Experimental Data. Int. J. Offshore Polar Eng. 2016, 26, 100-108. [CrossRef]

37. Huang, N.E.; Shen, Z.; Long, S.R. A new view of nonlinear water waves: The Hilbert Spectrum 1. Annu. Rev. Fluid Mech. 1999, 31, 417-457. [CrossRef]

38. Douglass, S.L.; Chen, Q.; Olsen, J.M.; Edge, B.L.; Brown, D. Final Report Prepared for U.S. Department of Transportation and Federal Highway Administration Office of Bridge Technology. In Wave Forces on Bridge Decks; Federal Highway Administration: Washington, DC, USA, 2006.

(C) 2019 by the authors. Licensee MDPI, Basel, Switzerland. This article is an open access article distributed under the terms and conditions of the Creative Commons Attribution (CC BY) license (http://creativecommons.org/licenses/by/4.0/). 